\title{
Carbohydrate Elimination or Adaptation Diet for Symptoms of Intestinal Discomfort in IBD: Rationales for "Gibsons' Conundrum"
}

\author{
Q. Manyan Fung and Andrew Szilagyi \\ Division of Gastroenterology, Department of Medicine, Jewish General Hospital, McGill University School of Medicine, \\ 3755 Côte-Sainte-Catherine Road, Room E110, Montreal, QC, Canada H3T 1E2 \\ Correspondence should be addressed to Andrew Szilagyi, aszilagy@gas.jgh.mcgill.ca
}

Received 15 September 2011; Revised 13 November 2011; Accepted 14 November 2011

Academic Editor: David Sachar

Copyright ( 2012 Q. M. Fung and A. Szilagyi. This is an open access article distributed under the Creative Commons Attribution License, which permits unrestricted use, distribution, and reproduction in any medium, provided the original work is properly cited.

\begin{abstract}
Therapeutic use of carbohydrates in inflammatory bowel diseases (IBDs) is discussed from two theoretical, apparent diametrically opposite perspectives: regular ingestion of prebiotics or withdrawal of virtually all carbohydrate components. Pathogenesis of IBD is discussed connecting microbial flora, host immunity, and genetic interactions. The best studied genetic example, NOD2 in Crohn's disease, is highlighted as a model which encompasses these interactions and has been shown to depend on butyrate for normal function. The role of these opposing concepts in management of irritable bowel syndrome (IBS) is contrasted with what is known in IBD. The conclusion reached is that, while both approaches may alleviate symptoms in both IBS and IBD, there is insufficient data yet to determine whether both approaches lead to equivalent bacterial effects in mollifying the immune system. This is particularly relevant in IBD. As such, caution is urged to use long-term carbohydrate withdrawal in IBD in remission to control IBS-like symptoms.
\end{abstract}

\section{Introduction}

A conundrum is defined by the American Heritage Dictionary of the English language [1] as "a riddle, especially one whose answer makes a play on words or as a puzzling question or problem." In 1995, Gibson and Roberfroid published their treatise on the potential benefits of maldigested carbohydrates on host health through manipulation of microflora [2]. The concept of prebiotics (nondigestible, highly fermentable, dietary substances that exhibit beneficial functions in the host by facilitating the growth and metabolic activity of either one or a selective number of healthpromoting colonic species) coincided with the emergence of potential human benefits found in probiotics (live bacteria bypassing the acid environment of the stomach and conferring health benefits to the host. A combination of pre- and probiotics is referred to as a synbiotic). A deluge of basic and clinical studies ensued as well, on the effects of prebiotics on an array of diseases. In particular, Crohn's disease (CD) and idiopathic ulcerative colitis (UC) (the two clinical subtypes of IBD) were targeted to capitalize on the potential therapeutic effects of either pro- or prebiotics [3-5]. While CD and idiopathic UC both share somewhat similar epidemiology and are thought to have originated from common genetic and environmental etiogenesis, they are in fact considered as two different entities. CD is unrestricted to any part of the gastrointestinal tract, in which the terminal ileum with or without the proximal colon remains the most common site affected. In UC, pathology tends to begin in the distal rectum and then it may proceed to involve the rest of the colon in a uniform fashion.

Similarly a benign but lifestyle-altering condition of irritable bowel syndrome (IBS- a chronic functional bowel disorder encompassed by frequent recurrences of abdominal pain is associated with altered bowel movements: diarrhea, constipation, or alternating form) also fell into the category potentially ameliorated by probiotics and perhaps prebiotics. In both of these conditions, however, it was postulated 


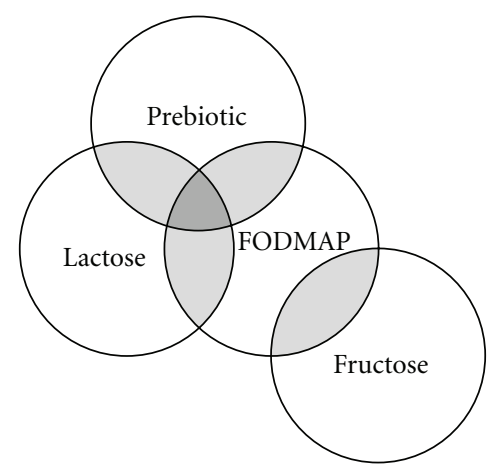

FIgURE 1: This Venn diagram shows the relationship between FODMAP, comprises of fructose, oligosaccharides, disaccharides, monosaccharides, and polyols. The central diet includes the majority of carbohydrates which are hypothesized to be malfermented by lower intestinal bacteria and therefore leading to excess production of gas and short-chain fatty acids with induction of symptoms. Thus, FODMAP includes all prebiotics in which lactose is included also as a restricted probiotic in lactose maldigesters. It is the hypothetical benefits of either withdrawal from diet or adapting to the prebiotic components of this diet that potentially forms a scientific conundrum in application.

that bacterial interactions, abnormal fermentation, and host handling of fermentative products as well as an immune response rather contributed to aggravation of symptoms $[6,7]$. In 2005, Gibson and Shepherd hypothesized such mechanisms in causation of gastrointestinal symptoms in these disorders and suggested that carbohydrates be withdrawn from diets of symptomatic IBS or IBD patients. This FODMAP diet suggests the withdrawal of fermentable oligo-, di-, monosaccharides, and polyols from the diet [8]. As such, the FODMAP diet includes lactose and most other prebiotics (refer to Figure 1 and Table 1). Some of these recommendations, of careful carbohydrate selection for diet in patients with IBD, were also suggested earlier in a book by Gottschall [9]. There was less emphasis on small molecules except for sweeteners and more on large complex carbohydrates.

The presentation of these two hypotheses, then, formulates a conundrum. In the first instance, carbohydrates bypassing absorption in the small intestine can specifically manipulate metabolism and benefit the commensal bacteria, which in turn help reduce inflammation. It is important to note that there are specific recognized prebiotics, but all carbohydrates interact with the microbiome. In the second scenario, a wide array of carbohydrates, including prebiotics, are withdrawn. Are the end results equivalent, that is, has a stimulated immune system been placated? A similar paradigm applies to use of probiotics [10] or antibiotics which have received some success both in IBD [11] and IBS [12-14] as well as to other dietetic interventions. These include enteral/polymeric diets and nonspecific exclusion diets that have previously been implicated for their therapeutic roles which are beyond the scope of this review [15].

Herein we will focus on discussing the rationales behind the usage or nonusage of FODMAP diet in IBD. Effects in IBS will be discussed overall, but the concept will be discussed in detail as it might apply to IBD based on current concepts of pathogenesis. The objectives are to review carbohydrate pathogenic interactions with intestinal immunity and to conceive an effective intervention that convenes the apparent hypothetical contradictions inherent in the two approaches to carbohydrate use.

\section{Microbial Diversity in the Gut}

2.1. Normal Development. The gastrointestinal microbiota (or microflora) differs among individuals and its dominant bacterial phylotypes are acquired from the moment of birth. Although intestinal microbial composition will remain fairly constant from early infancy throughout adulthood once bacterial colonization is established [16], these microorganisms respond adaptively to better accommodate and protect at an individual level. As such, fecal samples adequately reflect the colonic bacterial environment and indicate the individual's intestinal status in response to developmental changes, environmental factors, antibiotic usage, or illness. The recent advancement in molecular profiling methods, such as high-throughput sequencing of microbial $16 \mathrm{~S}$ ribosomal RNA genes [17] and metagenomics [18], provides a comprehensive insight into the 100 trillion bacteria that currently comprise the microbiota in the distal gastrointestinal tract alone. Representing the two predominant phylotypes found in mucosal and luminal microbiota are Gram-positive Firmicutes (species including Clostridia and Lactobacillaceae) and Gram-negative Bacteroidetes (species including Bacteroides), all of which are obligatory anaerobic bacteria.

2.2. Functions of the Microbiome. Sharing a symbiotic relationship with a dynamic bacterial community also means acquiring a diverse metabolic profile essential for intestinal development [19]. The resident microflora promotes the differentiation and proliferation of enteric epithelial cells by harvesting essential minerals (e.g., iron, calcium, and magnesium) as well as mediating the synthesis of vitamins (e.g., cobalamin, vitamin $\mathrm{K}$, biotin, pyridoxal phosphate, and tetrahydrofolate). In addition, the bacterial genome (also known as the microbiome) encodes a large repertoire of saccharolytic enzymes, including glycoside hydrolases and polysaccharide lyases, needed to further metabolize nondigestible carbohydrates such as plant polysaccharides (dietary fibers), oligosaccharides, lactose (especially in lactose maldigesters), and sugar alcohols in the proximal colon through a process called saccharolytic fermentation [18]. This colonic fermentation of macronutrients yields various end products like gaseous compounds (e.g., hydrogen gas, methane, and carbon dioxide) and short-chain fatty acids (SCFAs), with the latter being mostly comprised of acetate, propionate, and butyrate. These are utilized as the primary energy source for the colonic mucosa. Colonic concentration of SCFA substrates is determined not only by the consumption of dietary fiber but also by the bacterial species present in the microbiota. For example, the two prominent bacterial 
TABLE 1: List of poorly digested carbohydrates comprised of FODMAP and select prebiotics $(*)$, as well as their respective sources. This is not a complete list, and other complex carbohydrates which have effects on bacteria are also included in FODMAP.

\begin{tabular}{lc}
\hline Molecular form & Common sources \\
\hline Inulin $(*)$ & Onions, leeks, chicory, artichoke, wheat, banana \\
Oligofructose $(*)$ & Hydrolysis product of inulin \\
Short-chain fructo-oligosaccharide $(*)$ & Hydrolysis product of inulin \\
Trans galacto-oligosaccharides $(*)$ & Manufactured from lactose \\
Lactulose $(*)$ & Manufactured from lactose \\
Fructo-oligosaccharides $(*)$ & May be present in breast milk, formed from lactose \\
Isomalto-oligosaccharides $(*)$ & Present in foods, potential prebiotic \\
Lactose $(*)$ & Present in dairy products made from animal sources, prebiotic mostly in lactose maldigesters \\
Polyols & Sugar alcohols (sorbitol, mannitol, xylitol, maltitol, and isomalt), cauliflower, avocado, mushrooms \\
\hline
\end{tabular}

phylotypes each differs in the types of SCFAs produced, with Firmicutes selectively producing butyrate and Bacteroidetes controlling the levels of acetate and propionate production $[20,21]$. Small carbohydrates like lactose may also lead to production of butyrate through the stimulation of second tier bacteria (butyrogens) by initial breakdown products $[22,23]$. The presence of these organic acids helps induce an acidic environment unfavourable for the proliferation of strict anaerobic species $[24,25]$. Once carbohydrates are no longer available for fermentation, bacteria will proceed to proteolytic fermentation (less favourable) in the distal colon where proteins derived from diet, endogenous cellular proteins, and bacterial cells are catalyzed to toxic, carcinogenic metabolites (e.g., bacteriocins, ammonia, indoles, and phenols) [26]. These substances inhibit the growth or kill potentially pathogenic constituents. Another way the microbiota maintains resistance against colonization by pathogenic organisms is to compete for nutrients and attachment sites to the mucosal surface in the colon $[27,28]$. Minor perturbations in the intricate microbial diversity can have significant impact on the gut homeostatic balance [2932 ]. These changes have been implicated to predispose or contribute to conditions such as sepsis, IBS symptoms [6, $33]$, and even obesity in some populations $[34,35]$.

\section{The Interaction of the Microbiome with Intestinal Mucosal Immunity}

3.1. Mucosal Immune System. Intestinal mucosal immunity is associated with the integrity of the intracellular junctions in the gut epithelium constituting what is called a physical barrier. The mucosal integrity is further strengthened by what is called a chemical barrier thanks to a specialized group of differentiated epithelial cells residing in the paracellular space. Goblet cells, for instance, are responsible for secreting an overlying glycocalyx layer composed of mucin glycoproteins [36]; production of defensins, immunoglobulins, and other substances by enterocytes, lymphocytes, and Paneth cells (the last being generally restricted to the crypts of Lieberkuhn in the distal small bowel) can also be found within this mucus layer $[37,38]$. This dual barrier provides enhanced protection against unwarranted entry of luminal contents (including self- and non-self-antigens) into the systemic immune system, but this is also where innate immune recognition takes place. Many of the cells in this mucosal barrier respond to pathogens by expressing two functionally important subsets of pattern-recognition receptors (PRRs)—extracellular Toll-like receptors (TLRs) and intracellular nuclear oligomerization domain-(NOD-) like receptors. These assist in the detection of pathogenassociated molecular patterns (PAMPs) through the leucinerich repetitive (LRR) domain. Lipopolysaccharides (LPSs) and peptidoglycan (PGN) components (i.e., muramyl dipeptide) of bacterial cell wall are two examples of PAMPs. Each subset can either individually or convergently activate nuclear factor $\kappa \mathrm{B}(\mathrm{NF}-\kappa \mathrm{B})$ effector in the defense against foreign pathogens by producing inflammatory cytokines (e.g., TNF- $\alpha$ and IL-1 $\beta$ ) and antimicrobial peptides [39]. Chronic stimulation of PRRs by PGN can also produce inhibitory cytokines (e.g., TGF- $\beta$ and IL-10) via the NOD2dependent pathways to minimize excessive tissue injury induced by intestinal antigen-presenting cells [40]. Intestinal mucosal immunity is reinforced further by continuous interaction between epithelial cells and adaptive immune cells, including effector T-helper cells (Th1, Th2, and Th17), regulatory $\mathrm{T}$ cells (Foxp3+ Treg), and other immune cells (i.e., dendritic cell, macrophage, and natural killer cell) at the follicle-associated epithelium junction overlying the gutassociated lymphoid tissue [41].

Central to the discussion in conferring protection to the host is the influences of microbiota community on the normal development and homeostasis of mucosal immunity [52-54]. The symbiotic nature of the host-microbiota relationship is fundamental to the shaping of immunological function, balance, and tolerance in the gut. Paradoxically, the key for preserving such symbiotic coexistence in return depends on the robustness of the intestinal immune network, particularly in its ability to differentiate between symbiotic and pathogenic colonization. The maintenance of gut homeostatic balance, therefore, depends on the cooperation between mucosal immunity and microbial community, that is, if the right microbiota composition is present. Alteration to the microbial ecology, commonly referred to as dysbiosis, can distort intestinal immune responses by shifting the equilibrium between pro- and anti-inflammatory T-helper cells differentiation, as characterized by IBD pathogenesis (Box 1) [55-57]. 


\begin{abstract}
Classically, IBD (especially in CD) is associated with a hyperactive innate immune response producing unrestrained levels of proinflammatory cytokines and chemokines (e.g., IL-12, IFN$\gamma$, and TNF- $\alpha$ ), resulting in a marked expansion of lamina propria. This propagates further inflammation by recruiting T-helper $1\left(\mathrm{CD} 4^{+} \mathrm{Th} 1\right)$ cells. Alternatively, the opposite scenario can occur in which resident tissue macrophages fail in their attempt to initiate an innate immune response against foreign antigens and are defective in the secretion of proinflammatory cytokines $[42,43]$. Reduced concentrations of these mediators mean neutrophil recruitment cannot be adequately enforced at the lamina propria, resulting in impaired clearance of antigenic contents [44]. The following overcompensatory immune responses lead to either a polarization toward an atypical humoral phenotype driven by T-helper $2\left(\mathrm{CD} 4^{+} \mathrm{Th} 2\right)$ cells along with mediators such as IL-4 and IL-13 (especially in UC [45]) or recruitment of CD4 ${ }^{+}$Th1 cells [36]. The amplification of inflammatory response as an attempt to remove foreign material only incites further epithelial injury which coincides with a decreased production of defensins $[46,47]$. It is quite possible that both paradigms may be true given the genetic heterogeneity among IBD populations. A newly discovered subset of inflammatory T cells, known as T-helper 17 (Th17) cells, produces the proinflammatory cytokine IL-17 and requires IL-23 for proper maintenance and function. Indirectly, Th17 cells relate CD and UC etiologies due to IL-23 sharing similar subunits with another major cytokine found in the Th1 phenotype, namely, IL-12 $[48,49]$. Also, responsiveness to anti-TNF- $\alpha$ treatment suggests common pathogenic pathways are shared by both IBD subtypes [50, 51].
\end{abstract}

Box 1: IBD pathogenesis.

3.2. Concept of Dysbiosis and IBD. Analyses in the gastrointestinal microbial populations showed significant differences between healthy individuals and patients with IBD, an indication that dysbiosis may be a contributing factor to IBD $[58,59]$. Specifically, an increased propensity of obligatory aerobic bacteria is seen displacing the anaerobic species, with Bifidobacteria (in CD) [60] and Lactobacilli (in UC) [20] both being deficient in the microbiota. Reduced diversity of mucosa-associated phyla Firmicutes and Bacteroidetes is commonly observed as well in IBD controls [59, 61]. Depletion of Faecalibacterium prausnitzii is related to an activated immune response, which specifically suppresses and eradicates selective groups of bacteria resulting in an imbalance of intestinal flora [62]. This is relevant due to $F$. prausnitzii belonging to the genus Firmicutes in the Clostridia 14 cluster, which in fact is an important butyragenic-stimulated bacterium capable of exerting antiinflammatory effects [63].

Swidsinski et al. has shown that a person afflicted with IBD displays an intestinal mucosa heavily populated with adherent organisms which are virtually nonexistent in a healthy individual [64]. For instance, adherent-invasive E. coli are isolated and found to adhere to the brush border of primary ileal enterocytes of $\mathrm{CD}$ patients but none in healthy controls [65-67]. Most recently, however, Willing et al. demonstrated that specific bacterial changes were associated with different anatomical sites in CD but UC patients in remission shared a similar microflora as to healthy controls [68]. This correlates with the data gathered from a comparative microbiota analysis of mice where they found closely related phylotypes displayed higher abundances (cooccurrence) and are conducive to intestinal colonization irrespective of the microbial origin (external or internal) [69]. Highly abundant subsets of commensal microorganisms, such as Helicobacter, Clostridium, and
Enterococcus species, are hence more susceptible to transform the symbiotic nature of the host-microbiota relationship into a pathogenic one under certain environmental conditions [54]. Mucosal antibodies recovered from IBD subjects are found to be directed against intestinal commensal bacteria, as such, they may be more responsive to antibiotic treatment and faecal diversion than non-IBD controls [70, 71].

\section{The Relationship of Bacterial Metabolites of Carbohydrates and Mucosal Immunity}

4.1. Immunoregulatory Functions of Short-Chain Fatty Acids. Given that environmental-induced changes can alter the intestinal microbiota, leading to dysregulatory inflammatory responses, increasing evidence indicates that microbial fermentative by-products (e.g., acetate, propionate, and butyrate) demonstrate anti-inflammatory properties that may be clinically relevant to the treatment of IBD $[14,77,90-$ 93]. One study attributed the interaction between acetate and the chemoattractant receptor, G-protein-coupled receptor 43 (GPR43; also referred to as FFAR2) [94], critical in the regulation as well as the resolution of inflammatory responses [95]. By analyzing the transcription profiles of cellular receptor genes found in human leukocytes, the investigators had identified high degree of GPR43 expression in neutrophils and eosinophils; its expression was also closely governed by Toll-like receptors (TLR2 and TLR4), formyl peptide receptors (FPR1 and FPR2), and C5aR suggesting that GPR43 is important for innate immune and chemoattractant-induced responses. To examine the antiinflammatory protection conferred by the acetate-GPR43 signalling pathway, they induced acute colitis by adding dextran sulphate sodium (DSS) to the drinking water of GPR43-deficient $\left(\mathrm{Gpr}_{4} 3^{-/-}\right)$and wild-type mice for one 
TABLE 2: Some immunoregulatory functions of butyrate.

(i) Increases choline acetyltransferase immunoreactive (ChAT-IR) enteric neurons in vivo and in vitro

(ii) Increases cholinergic-mediated colonic motility and contractile response ex vivo

(i) Modulates oxidative stress in healthy colonic mucosa

(ii) Promotes glutathione (GSH) and lower uric acid concentrations compared

(i) Promotes the differential expression of 500 genes in human colonic mucosa

(ii) Increases gene expression of transcriptional regulation pathways: fatty acid oxidation,

electron transport chain, and oxidative stress

(iii) Increases gene expression related to epithelial integrity and apoptosis

(i) Influences colonic function, mainly by histone deacetylase inhibition

(i) Reduces inflammatory responses in vitro, mainly by inhibition of NF- $\kappa$ B activation

$[77]$

(i) Mediates NOD2-dependent mucosal immune responses against PGN

[78]

(i) Modulates an intracellular JAK/STAT1 signaling cascade which inhibits NO production

[79]

(i) Enhances upregulation/detection of PRRs on intestinal epithelial cells $[80-83]$

(i) Anticarcinogenic/angiogenic by modulating the activity of several key regulators involved in apoptosis and cell differentiation

week. Compared to the wild-type, Gpr43-1- mice exhibited exacerbated inflammatory response based on histological analysis, daily activity index (DAI; a combined measure of weight loss, rectal bleeding, and stool consistency), and increased levels of myeloperoxidase activity (MPO; inflammatory mediator) in the colon. A significant improvement to those inflammatory parameters soon followed after $200 \mathrm{mM}$ acetate was introduced in their drinking water in a GPR43dependent manner (Gpr43 ${ }^{-/}$mice lacked the receptor to respond to acetate but not in wild-type ones). Similar development of unresolved inflammation occurred in other mice models such as DSS-induced colitis in germ-free wildtype, $\mathrm{K} / \mathrm{BxN}$ serum-induced model of inflammatory arthritis and ovalbumin-induced model of allergic airway inflammation. Host protection against enteropathogen Escherichia coli $(0157: H 7)$ infection was recently linked to acetate production by Bifidobacteria [96]. They proposed that acetate prevented the pathogen from entering the systemic circulation by enhancing mucosal barrier defense.

Although acetate and propionate have long been shown to exert immunologic modification [14], it is butyrate which generates the majority of interest in research. The immunoregulatory activities exerted by butyrate are listed in Table 2. Butyrate is able to regulate multiple gene expressions in the colonic epithelial cells $[74,75]$. Inhibition of histone deacetylase by butyrate has been identified to orchestrate a series of downstream effectors responsible for its attributive anti-inflammatory profile [76, 97]. Most notably is the direct suppression of the NF- $\kappa \mathrm{B}$ transcription factor via histone acetylation, which in turn alters the transcriptional patterns of many genes encoding cytokines, chemokines, adhesion molecules, and other proinflammatory mediators [77, 98-101].

Other anti-inflammatory properties of butyrate highlighted as possible therapeutic targets in IBD include its ability to modulate an intracellular JAK/STAT1 signalling cascade which reduces NO production in macrophages and in intestinal myofibroblasts [79]; enhance the upregulation/detection of PRRs on intestinal epithelial cells (e.g., TLR1, TLR4, TLR6, peroxisome proliferator-activated receptor- $\gamma(\operatorname{PPAR} \gamma))$ [80-83], hence facilitating the migration of neutrophil [102]; mitigate the extent of DNA damage in colonocytes induced by neutrophilic oxidizing species during carcinogenesis $[103,104]$; potentiate the expression of heat shock proteins, especially HSP70 and HSP25, in enterocyte-like Caco-2 cells and DSS-induced colitis which further enhances cellular protection during an inflammatory response $[105,106]$.

In some cultured cell lines, butyrate improved the status of intestinal defense mechanisms commonly impaired in IBD by restoring mucosal barrier integrity and promoting epithelial migration in a dose-dependent manner [87-89]. Specifically, its administration has been demonstrated to stimulate MUC2 mucin gene expression in which its protein product is often altered in IBD [107-109]. An increased mucin secretion has also been reported in the isolated vascularly perfused rat colon [110]. Butyrate was also demonstrated to modulate the expression of antimicrobial peptide, cathelicidin (LL-37), in isolated colon epithelial cell lines [111]. A reinforced mucus layer and epithelial tight junctions mean decreasing mucosal permeability, making foreign substances impossible to pass through the defense barrier.

To date potential therapeutic effects of butyrate have been limited to UC. Interestingly, in vivo studies have shown that butyrate oxidation in the colon mucosa of patients with quiescent UC remain normal, whereas those with an actively inflamed mucosa do not [112]. It was reported that TNF$\alpha$, an inflammatory mediator, may be responsible for the reduced colonic uptake of butyrate [113]. The deprivation of butyrate or any other SCFAs, in conjunction with the toxic metabolites derived from proteolytic fermentation when saccharolytic fermentation is not possible, has long been proposed for the pathogenesis of gastrointestinal disorders 
(or even cancer) identified to originate in the distal colon [114]. Similar proposal concerning their therapeutic role in the regulation of inflammatory immune responses and the defense of mucosal immunity with respect to cellular functions in the colon is also made [26, 115-117]. The therapeutic effects of either butyrate alone or combination of SCFAs on patients with moderate-to-active colonic inflammation were confirmed. Many of the UC patients showed responsiveness toward rectal enema treatment of butyrate (amid methodological and procedural differences), whereby symptomatic improvement was reported afterward and coincided with a reduction in the inflammatory parameters $[93,118,119]$. Despite the fact that clinical data have not established an efficacious dietary quantity/frequency of butyrate [120-122], current in vitro and ex vivo studies do implicate a regulatory role in intestinal mucosal immunity.

\section{Genes and IBD}

Disease expression observed in individuals with IBD are a result of genetic predisposition to mounting an inappropriate inflammatory response toward commensal microflora (i.e., anergy is breached) $[123,124]$. Some view immunodeficiency phenotype as the principle drive behind IBD pathogenesis $[125,126]$, but external variables including degree of bacterial load, malnutrition, surgery, and/or use of immunosuppressant therapy must be present in order to facilitate the disruption of the mucus layer and/or epithelial tight junctions. As a result, rendering the submucosal compartments to become increasingly susceptible to bacterial exposure, penetration, and adherence [36, 127-130]. Most importantly, these variables predispose to abnormal interactions with the microbiota. Whether observed dysbiosis, particularly in $\mathrm{CD}$, is a result of the host reaction and/or therapy or a precursor to disease development is unclear yet.

Early progress was centered on characterizing genetic variations in association with IBD susceptibility as supported by familial aggregation studies and population-based cohort surveys. It was suggested that geographic location, ethnic background, socioeconomic class, and positive familial IBD history (e.g., first-degree relatives and monozygotic twin) are all variables dictating the risk in an individual for developing IBD $[131,132]$. Out of the $71 \mathrm{CD}$ candidate genes and 47 for UC that have been identified to date [133], only about 30 of them are clearly delineated [50]. Genetic studies are providing more concrete evidence for earlier epidemiological studies, but at the same time pose additional questions that further highlight the complex etiologies associated with IBD. Despite some similar phenotypic traits, IBD subtypes do not share all susceptibility loci. Another key finding reveals that allelic variants to date confer to only a small fraction of disease heritability in the IBD populations. This suggests that as yet unidentified genes or other environmental factors are attributable to IBD pathophysiological development. Indeed in $\mathrm{CD}$ genetic predisposition to bacterial infections is generally not enough to bring forth the clinical symptoms. A number of additional environmental factors have now been delineated, and these include smoking (promotes CD and protects against UC) [134], appendectomy (may promote CD and protects against UC) [135], nonsteroidal antiinflammatory drugs (promote CD) [134], bacterial or viral infections (disrupt mucosal permeability of the intestine) [134], and early exposure to antibiotics (promote CD) [136].

5.1. Mechanistic Model of Genetic, Nutrient, Microbial Interaction: Function of NOD2. The first and most consistent mutations associated with increased susceptibility of CD (but not UC) are in the nucleotide-binding oligomerization domain containing 2 (NOD2) gene located on chromosome 16q12. Formerly it was known as caspase activated recruitment domain protein 15 (CARD15) gene [39]. Considerable research has revealed a complex of interactive components necessary for the normal function of disposing the host of bacterial invaders. This section reviews the components, genetic and dietary, needed for such function. It is used primarily here as an example of the mechanistic interactive effects outlined above and how dysfunctions in different components could lead to disease.

Nod2 protein (product of the NOD2 gene) belongs to the family of PRRs. Upon recognition of bacterial-associated PGN patterns, it mediates the activation of two pathways$\mathrm{NF}-\kappa \mathrm{B}$ and mitogen-activated protein (MAP) kinase. This intracellular receptor located predominantly in Paneth and other cells situated in the distal ileum plays a key part in the innate immune defense by eliminating intracellular bacteria or bacterial debris [137]. Its genetic mutations confer susceptibility in CD mice models [138]. Three major NOD2 mutations associated with the LRR domain have been confirmed: two missense SNPs (Arg702Trp and Gly908Arg) and one frameshift variant (Leu1007fsinsC), respectively [139-141]. All three mutations share similar restricted activation of the $\mathrm{NF}-\kappa \mathrm{B}$ pathway in response to LPS and PGN treatments $[140,142,143]$. Despite the prevalence of NOD2 mutations present among the Caucasian populations (approximately $30 \%$ of patients of European ancestry have at least one of the three polymorphisms), the genetic penetrance corresponds to less than $10 \%$ of $\mathrm{CD}$ manifestation found in the carriers $[144,145]$.

5.2. Genetic Components for Normal NOD2 Function. A number of genes interact to promote normal NOD2 function. These include genes controlling Toll-like receptors, autophagy genes (ATG16L1 and IRGM), and most recently, products of Transducin-like enhancer of split 1 (TLE1) also demonstrate major effects. Even though loss of function/regulation in NOD2 may not compromise NF- $\kappa \mathrm{B}$ signalling completely, an imbalance of immune activity among mucosal cells is often the case due to oversecretion of proinflammatory cytokines as an attempt to dispose bacterial components [146]. A recent paper reported that TNF receptor 4 (TRAF4) is responsible for downregulating the activation of NF- $\kappa \mathrm{B}$, hence limiting the innate response. This indicates that mutations in this downregulator may be key in correcting the acute innate response similar to how bacterial inoculation could do for NOD2 polymorphisms [147]. 
Autophagy is a highly conserved cellular process recognized for its role during starvation and in intracellular pathogen clearance. In the former, intracellular components are degraded indiscriminately to ensure cell viability. In the latter case, the process involves the precise rearrangement of intracellular constituents (e.g., bacteria, mitochondria, intracellular membranes, and proteins) to form a macroautophagy structure in order to isolate the foreign pathogen for digestion. It is then sequestered in a double-membrane cytosolic vacuole called an autophagosome which later fuses with lysosomes for further processing [148, 149]. Genomewide association (GWA) studies have identified two sequence variants involved in the autophagy pathway, ATG16L1 and IRGM1, which confer to the genetic susceptibility of CD [150-153]. Although the functional consequences as to how ATG16L1 and IRGM1 mutations contribute to the pathogenesis of CD are not fully understood, accumulating human genetic data suggest that the location of ATG16L1 risk allele on chromosome 2q37 might be linked to autophagy mutations found in macrophage and Paneth cell.

Most recently a number of proteins have been identified in vitro to interact with NOD2 [154]. Using a yeast 2-hybrid screen some have been connected to a gene TLE1 which affects mucin biosynthesis and apoptosis. These epistatic interactions are putatively regulatory, and mutations in one of the alleles of TLE1 appear to be necessary for CD risk in the presence of classical NOD2 mutations. This allele may also increase the risk for UC which is independent of NOD2 mutations.

5.3. Nutrient Components for Normal NOD2 Function. In addition to the genetically mediated controls outlined for NOD2, two environmental variables have been shown as requirements for normal execution of intracellular bacterial elimination. One study by Wang et al. linked in vitro 1,25dihydroxyvitamin $\mathrm{D}$ (or vitamin $\mathrm{D}$ ) requirement for normal NOD2 function which was measured through the release of stimulated NF- $\kappa \mathrm{B}$ products and defensin $\beta 2$ [155]. The presence of mutations of NOD2 could not be corrected by increasing media levels of vitamin $\mathrm{D}$. The other paper by Leung et al. reported that, in response to the selective modulation of histone acetylation in the NOD2 promoter region by butyrate, an upregulation of Nod 2 was observed. The result is a dramatic enhancement in the production of two chemokines, IL- 8 and GRO- $\alpha$, in the presence of PGN. However, in its absence, butyrate only had a slight effect on IL- 8 concentration without altering the NF- $\kappa$ B associated IL- 8 promoter region concentration levels. Their results are in agreement with the observation made by Fusunyan and colleagues, such that NF- $\kappa \mathrm{B}$ suppression by butyrate is an indication that the upregulation of IL- 8 must be independent of NF- $\kappa \mathrm{B}$-mediated mechanism $[78,100]$. Butyrate addition to the in vitro Caco- 2 cell line enhanced PGN-mediated IL8 and GRO- $\alpha$ production. These products also depended on the induction of NF- $\kappa \mathrm{B}$ as well as PGN [78]. Taken together these two reports outline a molecular model for the interactions between the NOD2 genetic consortium and 2 important environmental variables which impact on normal function. To date there is no information to our knowledge whether these 2 variables, vitamin $\mathrm{D}$ and butyrate, serve redundant or synergistic (additive) functions. Until that time the role of butyrate may be essential for appropriate clearance of intracellular bacterial products and innate immunity.

\section{Dietary Carbohydrates, Symptoms, Pathogenesis}

The impact of dietary interventions for the management of IBD has kept abreast of the scientific research outcome in the last two to three decades, albeit that results are less compelling than theory would suggest. Rationales for specific interventions in particular are more defined. For example, the use of anti-inflammatory omega- 3 fatty acids seems rational, although outcomes are not satisfactory $[172,173]$. In the case of carbohydrates, Gibson and Shepherd argue that distribution and subsequent rapid fermentation of FODMAP molecules predispose the distal small intestinal and colonic lumen to increased intestinal permeability, an underlying factor to the development of CD in genetically susceptible individuals [8]. They have advocated the pathophysiological involvement of FODMAPs in $\mathrm{CD}$ as a direct consequence of widespread consumption in Western societies. Excessive exposure of high fructose corn syrups and caloric sweeteners, commonly present in soft drinks and various manufactured food products [174], also appear to correlate with an increase in functional GI symptoms. As well, lactose sensitivity, independent of known genetic lactase status, has now been confirmed in patients with CD [160].

Consumption of FODMAPs exerts osmotic effects by increasing luminal fluid, inducing intestinal distension, altering intestinal contractile patterns, and accelerating transit time [175]. Development of these symptoms leads to the concept of global restriction of all poorly absorbed, rapidly fermentable short-chain carbohydrates as opposed to selectively limiting a few food items [176-178]. FODMAPs aggravate symptoms possibly further by inducing abnormal motility patterns as a consequence of colonic microfloral modification to accommodate the high volume of such consumption [163] or the incompletely evaluated role of intestinally released gut hormones as described with the prebiotic lactulose $[179,180]$.

\subsection{Effects of Carbohydrate Withdrawal on Microbial Flora.} Early etiological studies of IBD (especially CD) have consistently suggested that high consumption of refined sugar may be an independent risk factor [181-185]. More recent publications, however, have questioned this effect [186-188]. Nevertheless, a possible explanation for this observation has been provided by the proposed prebiotic concept [2]. There are, however, little data on microbial effects of complex carbohydrate withdrawal. Rats restrictive of food for 20 weeks resulted in nonsignificant changes in reduction of total anaerobic microbes and no significant shifts in population species [189]. When rats were fed sucrose or starch in equicaloric amounts for 9 months, no weight changes occurred, 
TABLE 3: Comparison of putative pathogenic mechanisms in inflammatory bowel disease (IBD) and irritable bowel syndrome (IBS).

\begin{tabular}{llr}
\hline & (i) Genetic predisposition (extensive) & {$[39,131,140,150,152,156,157]$} \\
(ii) Intestinal microflora alterations & {$[55-57,59-61,65,124,158,159]$} \\
(iii) Altered immunity (extensive) & {$[42-44,123,125,126]$} \\
(iv) Altered carbohydrate sensitivity & {$[160]$} \\
(v) Tissue destruction and complications & {$[50,124]$} & {$[161,162]$} \\
& (i) Genetic predisposition (exists but not yet worked out) & {$[6,33,163-165]$} \\
(ii) Microflora alterations especially after gastroenteritis & {$[166]$} \\
(iii) Altered immune response (variable and mild) & {$[167-170]$} \\
(iv) Altered carbohydrate sensitivity & (v) No evidence for tissue destruction
\end{tabular}

but the aerobic population increased and ratio of anaerobes to aerobes decreased [190]. Most importantly the total SCFAs production was significantly higher in starch than sucrosefed rats, although the ratios remained the same.

6.2. Effects of Carbohydrate Feeding on Microbial Flora. On the contrary there are abundant data on the effects of poorly digested carbohydrates on microflora. Maldigested carbohydrates in general alter numbers [191] and type of intestinal cells [192], SCFAs production, colonic $\mathrm{pH}$ [191, 193], and microbial numbers as well as diversity [194]. As for prebiotics (those maldigested carbohydrates which fit more to the definitions as proposed by Gibson et al. [195]), short-chain (oligofructose) as well as long-chain fructose (inulin) polymers, all of which promoted the production of SCFAs [196], Bifidobacteria and Lactobacilli species in stool [197, 198], and other mucosal-associated microbial species [199].

In the case of IBD, the introduction of fructooligosaccharides or lactulose in healthy rats has demonstrated a combined effect of increased bacterial translocation, epithelial cell proliferation, colonic epithelial injury, and mucin production despite prebiotic consumption [200]. Among rats fed a FODMAP-like diet in conjunction with Salmonella species infection, severe colitis developed while only mild colonic inflammation was observed in controls [200].

Furthermore, a number of other published studies have demonstrated the protective role of both traditional prebiotics as well as other maldigested carbohydrates against experimentally-induced colitis (reviewed in [5]). The animal models employed in those experiments include the IL-10deficient and trinitrobenzene sulfonic acid (TNBS) mouse model of CD and the DSS mouse model of UC. In these cases lactulose, fructo-oligosaccharide, and trans-galactooligosaccharide prebiotics as well as germinated barley foodstuffs (derived from beer production) alter colonic physiology via $\mathrm{pH}$, SCFAs production, microbial species, and outcome of induced colitis.

Probiotics and prebiotics have generally been associated with improvement in clinical IBD [201]. It is postulated that pro- and prebiotics modulate the extent of inflammation during the progressive stage of the condition. In this context probiotics may have an advantage in UC [202], despite benefit of any specific probiotic in CD to date has not been substantiated [203]. Prebiotics in CD have generally shown some effect but again not substantiated (see the following).

6.3. Irritable Bowel Syndrome and Inflammatory Bowel Disease. An example where dietary intervention takes into consideration both outlined concepts of carbohydrate effects is IBS. Neurological disturbances [204-207], abnormalities in the brain-gut axis [208, 209], hyperreactivity to stress [210], and impaired gut motility or transit [211, 212] are etiological factors previously proposed to drive symptom profiles of IBS. However, until recently etiological explanations have begun to resemble those of IBD. Genetic factors [161], altered enteric microbiota [164], with a variation of additional bacterial overgrowth in the small intestine [33], and the role of host-microbial communications are gaining importance $[6,7,162,165,213]$. High production of acetate and propionate have been observed in correlation with more severe IBS symptoms in patients as reported by Tana et al. [214]. Response to selective probiotics in IBS has also been reported albeit with variable success [10]. While there may be some increased inflammatory cells found on histopathology $[166,215]$, in cases of postinfection, there is no tissue destruction as seen in IBD. Table 3 outlines some of these similarities.

In general, symptoms in active IBD are attributed to inflammatory processes. However, a fraction of patients defined by clinical criteria to be in remission, nevertheless suffer symptoms which are reminiscent of IBS and satisfy Rome II or III criteria [216]. The use of classical antiinflammatory medication (e.g., corticosteroids, immunomodulators, etc.) does not seem to alleviate these symptoms and may affect up to a third of patients [216]. Nonetheless, evaluation of fecal calprotectin (a protein marker of true inflammation) in such patients shows elevated levels supporting the notion that these IBS-like symptoms may also be mediated by inflammation. Generally, calprotectin levels are expected to be normal in classical IBS [217].

At present, therapeutic developments targeting those factors remain a complicated task due to the heterogeneity within and among individuals. Unlike IBD, which has a defined immunological pathology, IBS is a highly subjective disorder where hypersensitivity to foodstuffs is mistakenly 
perceived by patients as the primary symptomatic factor (the common ill-perceived food constituents are ones originating from dairy products, fructose and wheat products) $[167,168,208]$. Carbohydrate ingestion, in particular, are often avoided. There are thus two approaches to reduce the symptoms as a result of carbohydrate ingestion. Both will be discussed in the following.

\section{Concepts of Carbohydrates and Therapy: FODMAP Withdrawal Approach}

7.1. Irritable Bowel Syndrome. After having incorporated FODMAPs as part of their daily diet, subjects (those with preexisting IBS, quiescent IBD condition, or free of intestinal diseases) across several studies had all experienced an increase in effluent load, diarrhea secondary to altered bowel/motility movements, and an overall exacerbation of abdominal symptoms (i.e., flatulence, pain, and bloating) $[169,178]$. Contrarily, results derived from other studies involving the restriction of one or more FODMAP food items all showed an improvement of abdominal symptoms in IBS patients [170, 218].

Twelve participants who had previously undergone ileostomy were subjected to either a high or low FODMAP diet for a 4-day period [178]. A $20 \%$ increase in the ileal effluent was observed after the participants consumed a high FODMAP diet compared to low, taken into account water content and dry weight also. The effluent consistency was reportedly thicker for the low FODMAP diet as opposed to the high FODMAP diet. Such changes to the nature of ileostomy output are likely influenced by the osmotically active FODMAP components.

Isolated fructose restriction for IBS patients with fructose malabsorption also demonstrated a sustained improvement of functional gut symptoms [218]. In a randomized placebocontrolled crossover trial, fructose, fructans (these are linear or branched polymers of fructose) and a mixture of the two substrates were randomly reintroduced to the original low FODMAP test diet given to a group of fructose malabsorbers with some form of known IBS condition [169]. Despite responding well to the low FODMAP diet for the 10-day duration, $70 \%$ of these patients reported symptom recurrence (i.e., diarrhea, abdominal pain, wind, bloating, etc.) upon having their daily meal challenged with fructose and/or fructans in a dose-dependent manner compared to only $14 \%$ who received glucose (control). In addition, fructose and fructan combined promoted the greatest symptom severity than either substance alone. This study further supports the dietary principles of FODMAP withdrawal and demonstrates how eliminating the right dietary component is critical to correct IBS symptoms.

It is postulated that the many symptoms (especially diarrhea) felt by IBS patients may be more related to abnormal colonic fermentation rather than osmotic effects, possibly a result of antibiotic- or gastroenteritis-induced dysbiosis [163]. One experiment assessed such correlation by measuring the total body excretion of hydrogen and methane gas in a 24-hour calorimetric test [219]. A comparison between healthy and symptomatic IBS subjects, each consuming two types of diet-a standard fiber-rich and fiber-free diet-found that a significant improvement in abdominal symptoms is in fact associated with the reduction of gaseous products from fiber-free consumption.

Ong and colleagues conducted a randomized, singleblinded, crossover trial to evaluate the impact FODMAP consumption has on the extent and spectrum of intraluminal gas production in 15 healthy volunteers compared to 15 IBS patients by Rome III criteria [220]. Breath hydrogen excretion levels remained fairly high in both groups after a 2day high FODMAP diet. They observed that those subjected to a high FODMAP diet have a significantly higher incidence of symptoms associated with luminal extension. Interestingly, those without IBS criteria also reported increase in gas production when subjected to a high FODMAP diet, but it did not translate to IBS-related symptoms [220]. Thus, these results indicate that FODMAPs do not cause IBS but that symptoms are triggered by the exaggerated bowel response to gaseous distension $[169,220]$. Another study from the UK confirmed the benefit of a low FODMAP diet in IBS patients [221]. Staudacher et al. conducted a diet questionnaire in 82 patients with IBS where they were roughly divided into equal proportions to consume either a standard or a low FODMAP diet. Both groups showed significant improvements in the overall and specific symptoms (e.g., bloating).

7.2. Inflammatory Bowel Disease. In the case of IBD, little information is available concerning the specific trials involving carbohydrate restriction. The use of elemental/enteral diets particularly in children to induce $\mathrm{CD}$ remission has been explored, but it involves the restriction of most elements from reaching the lower intestine [222, 223]. A randomized controlled trial of carbohydrate restriction was reported by Lorenz-Meyer et al. after 15 years of study [224]. They found some benefit to prevention of relapse in patients with $\mathrm{CD}$, but intention to treat analysis failed to reach significance. More recently, FODMAP withdrawal was reported in a pilot study of 72 patients (52 CD, $20 \mathrm{UC}$ ) over a 3-month period [225]. Out of about $70 \%$ diet-adherent patients, $50 \%$ responded favourably with reductions in abdominal symptoms.

\section{Concepts of Carbohydrates and Therapy: Emphasis on Prebiotics}

8.1. Irritable Bowel Syndrome. In contradistinction to FODMAP withdrawal diet, regular consumption of single or mixtures of prebiotics has also been explored for IBS in a few studies. The concept that symptoms of carbohydrate intolerance in healthy persons can be overcome by regular short-term ingestion was observed in populations with lactose intolerance [246]. A formal randomized crossover study of lactose feeding in lactose maldigesters demonstrated both symptomatic and fecal microfloral adaptation [247]. Although symptomatic improvement of lactose intolerance may be due to a placebo effect [248], changes in hydrogen and fecal bacteria are physiological [249-251]. 
TABLE 4: (a) Human studies published on the use of prebiotics or nondigestible carbohydrates for inflammatory disorders. IBD: inflammatory bowel disease, UC: ulcerative colitis, CD: Crohn's disease, and P: postoperative ileoanal anastomotic pouch inflammation, represents a spectrum of IBD recurrences. (b) Studies using combination of prebiotics and probiotics (synbiotics) for IBD.

(a)

\begin{tabular}{|c|c|c|c|c|c|}
\hline Disorder & $N=$ patients & Study type & Active agent & Outcome & Reference \\
\hline $\mathrm{UC}^{1}$ & 29 & RCT & Ispaghula husk & Improved & {$[226]^{*}$} \\
\hline $\mathrm{UC}^{1}$ & 102 & RCT, OL & Plantago Ovata & Nonsuperior & {$[227]$} \\
\hline $\mathrm{UC}^{2}$ & 10 & $\mathrm{OL}$ & $\mathrm{GBF}$ & Improved & {$[228]$} \\
\hline $\mathrm{UC}^{2}$ & 18 & $\mathrm{OL}$ & GBF & Improved & {$[91]$} \\
\hline $\mathrm{UC}^{2}$ & 21 & $\mathrm{OL}$ & GBF & Improved & {$[229]$} \\
\hline $\mathrm{UC}^{2}$ & 40 & RCT & GBF & Cytokine decreased & {$[230]$} \\
\hline $\mathrm{UC}^{1}$ & 59 & RCT, OL & GBF & Lower recurrence & {$[231]$} \\
\hline $\mathrm{UC}^{2}$ & 19 & $\mathrm{OL}$ & $\mathrm{OFS}+\mathrm{IN}+\mathrm{Bif}$ & Improved clinical endoscopy & {$[232]$} \\
\hline $\mathrm{UC}$ and $\mathrm{CD}^{1}$ & 20 (10 controls $)$ & $\mathrm{OL}$ & Lactulose & Adaptation in UC, but not in CD & {$[233]$} \\
\hline $\mathrm{UC}$ and $\mathrm{CD}^{1}$ & 31 & $\mathrm{OL}$ & Lactulose & No effect, but improved quality of life in UC & {$[234]$} \\
\hline $\mathrm{CD}^{2}$ & 10 & $\mathrm{OL}$ & FOS, IN & Improved score & {$[235]$} \\
\hline $\mathrm{CD}^{2}$ & 10 & $\mathrm{OL}$ & FOS, IN & Improved & {$[236]$} \\
\hline $\mathrm{CD}^{2}$ & 103 & DBRCT & FOS & No clinical benefit, despite impacting on DC function & [237] \\
\hline $\mathrm{P}^{2}$ & 20 & DBRCT & IN & Improved inflammation & {$[238]^{*}$} \\
\hline $\mathrm{P}^{2}$ & 21 & $\mathrm{OL}$ & Lactose & Decreased bacterial sulfomucins & [239] \\
\hline
\end{tabular}

(b)

\begin{tabular}{lccccc}
\hline Disorder & $N=$ patients & Study type & Active agent & Outcome & Reference \\
\hline $\mathrm{UC}^{2}$ & 16 & OL & OFS + IN + Bif & Improved clinical endoscopy \\
$\mathrm{UC}^{1}$ & 120 & RCT & Bif/Psy/Bif + Psy & Improved quality of life with Bif + Psy & {$[240]$} \\
$\mathrm{CD}^{3}$ & 30 & OL & Mixed fiber + IN + 4 Lacto & Failed to prevent relapse \\
$\mathrm{CD}^{2}$ & 10 & OL & Psy + Bif + Lacto & Clinical improvement & [242] \\
$\mathrm{CD}^{2}$ & 35 & DBRCT & OFS + IN + Bif & Clinical improvement & Improved and remit \\
$\mathrm{P}^{2}$ & 10 & OL & OFS, Lacto & {$[244]$} \\
\hline
\end{tabular}

RCT: randomized controlled trial; DBRCT: double-blind randomized controlled trial; OL: open labeled; GBF: germinated barley foodstuffs; FOS: fructooligosaccharides (<5 degrees of polymerization); OFS: oligofructose (5-10 degrees of polymerization); IN: inulin (<200 degrees of polymerization); Psy: psyllium; Bif: Bifidobacteria species; Lacto: Lactobacillus species.

$*$ Crossover design,

${ }^{1}$ Disease in remission,

${ }^{2}$ Active disease,

${ }^{3}$ Maintenance after surgery.

While it is well recognized that prebiotics induce symptoms in patients, there are now two controlled trials in patients with IBS which demonstrated symptomatic "adaptation" to prolonged feeding. Paineau et al. published a doubleblind randomized controlled trial using short-chain fructooligosaccharides in 105 patients and reported a global, yet highly specific, symptomatic improvement by the end of the 6-week trial [252]. Similarly, trans-galacto-oligosaccharides employed by Silk et al. in a crossover trial of 44 patients over 12 weeks also reported global and specific improvements [253]. These two studies demonstrate that it is possible to improve symptoms in IBS simply by providing prebiotics on a continual basis. It is not, however, clear whether such improvements were due to "psychological adaption" or bacterial adaptation to carbohydrates.

8.2. Inflammatory Bowel Disease. Several studies examining the possible benefits of classical prebiotics (fructose or galactosyl polymers) and poorly digested fibers (e.g., Ispaghula husk, germinated barley foodstuffs) to IBD have been published. The rationale as outlined rests on their ability to modulate the intestinal microflora and their beneficial consequences associated with SCFAs production $[91,206]$. These studies comprised of 744 patients with UC, CD, or P (postoperative ileoanal anastomotic pouch inflammation). The variety of indications is described in Tables 4(a) and 4(b), and includes maintenance of remission [226, 227, 231, 234], mild to moderately active disease $[91,228-230,232$, 236-240, 244], prevention of postsurgical CD recurrence $[226,242]$, and physiological assessment of adaptation capability [233]. The studies include 8 randomized controlled trials of which 3 were double blinded $[237,238,244]$ and two were crossover design $[226,238]$. The studies extended from 2 weeks to 24 months (mean $4.8 \pm 6.1$ months, with a median of 1.6 months). A total of 510 patients were treated with active agent and 234 were controls. Of the controls 31 patients received probiotics without prebiotics [241]. Forty-nine treated patients were crossed over to placebo 
[226, 238]. While endpoints varied, only two studies failed to show benefit. Six of the randomized studies ( 4 for UC in remission [226, 227, 241], one active CD [244], and one active $\mathrm{P}$ [238]) showed better or nonsuperior remission rates for UC, also improvement in clinical score for CD or P. A small study showed reduction of proinflammatory cytokines in UC [230]. However, the studies failing to show benefit included the largest and most carefully conducted DBRCT (double-blind randomized controlled trial) of patients with active CD [237]. Importantly, it also included the only study albeit observational, evaluating the role of synbiotics in CD postsurgery recurrence [242]. Additional well-conducted trials are needed to lend clinical credence to effective use of prebiotics in IBD.

\section{Summary and Conclusions}

The basic premise of this paper is a conceptual contrast of the rationale of either using a select group of prebiotic molecules to alter microflora and microbial metabolism or to withhold a wide array of carbohydrates which includes those prebiotics. The emphasis of these interventions is on use in IBD, but IBS is used as a clinical model to outline available but to date limited number of trials to show symptomatic efficacy. The two principles pose a scientific conundrum particularly in IBD, while there is evidence that bacterial immune interactions play a significant role in IBS abnormal immune response in IBD lead to tissue destruction.

There is limited evidence that both approaches (withhold FODMAP entirely or use selective parts of FODMAP) in IBS result in symptomatic improvement in a significant percentage of patients within a certain time frame. The use of prebiotics in IBD is not settled in either active or remitting disease. Information on the use of FODMAP or general carbohydrate withdrawal, to our knowledge, has been limited with IBD. The IBS-like symptoms in IBD may be related to intestinal inflammation making its pathogenesis similar but different from that in true IBS. As such the role of beneficial bacteria and SCFAs may be more important in the former.

The real "conundrum," then, is whether the additive or withdrawal approach can induce microbial changes which subsequently lead to amelioration of symptoms (as in IBS or IBS-like symptoms in IBD), but also modulation of the immune response especially inflammation. If both approaches affect the microflora, what organisms are (equally?) modulated by a reduction in specific nutrition as well as kept in check by other organisms like lactic acidproducing bacteria? There is limited research on effects of withdrawal (whether total nutrient or specific nutrients like carbohydrates). There are many publications on effects of addition of prebiotics or complex fibers. The example of NOD2 suggests that certain dietary components may be necessary for normal function, but redundant functions are likely. Nevertheless, until more information is available, a judicious use of the discussed approaches and time of use should be considered for symptom control, with withdrawal (the less tried approach) for IBD.

\section{References}

[1] The American Heritage Dictionary of the English Language, Houghton Mifflin, Boston, Mass, USA, 2000.

[2] G. R. Gibson and M. B. Roberfroid, "Dietary modulation of the human colonic microbiota: introducing the concept of prebiotics," Journal of Nutrition, vol. 125, no. 6, pp. 1401$1412,1995$.

[3] C. Hedin, K. Whelan, and J. O. Lindsay, "Evidence for the use of probiotics and prebiotics in inflammatory bowel disease: a review of clinical trials," Proceedings of the Nutrition Society, vol. 66, no. 3, pp. 307-315, 2007.

[4] C. H. M. Leenen and L. A. Dieleman, "Inulin and oligofructose in chronic inflammatory bowel disease," Journal of Nutrition, vol. 137, no. 11, pp. 2572S-2575S, 2007.

[5] A. Szilagyi, "Use of prebiotics for inflammatory bowel disease," Canadian Journal of Gastroenterology, vol. 19, no. 8, pp. 505-510, 2005.

[6] E. M. M. Quigley, "Bacterial flora in irritable bowel syndrome: role in pathophysiology, implications for management," Journal of Digestive Diseases, vol. 8, no. 1, pp. 2-7, 2007.

[7] U. C. Ghoshal, H. Park, and K. A. Gwee, "Bugs and irritable bowel syndrome: the good, the bad and the ugly," Journal of Gastroenterology and Hepatology, vol. 25, no. 2, pp. 244-251, 2010.

[8] P. R. Gibson and S. J. Shepherd, "Personal view: food for thought-western lifestyle and susceptibility to Crohn's disease. The FODMAP hypothesis," Alimentary Pharmacology and Therapeutics, vol. 21, no. 12, pp. 1399-1409, 2005.

[9] E. G. Gottschall, Breaking the Vicious Cycle: Intestinal Health Through Diet, Kirkton Press, Ontario, Canada, 1994.

[10] G. Aragon, D. B. Graham, M. Borum, and D. B. Doman, "Probiotic therapy for irritable bowel syndrome," Gastroenterology and Hepatology, vol. 6, no. 1, pp. 39-44, 2010.

[11] S. L. Greenbloom, A. H. Steinhart, and G. R. Greenberg, "Combination ciprofloxacin and metronidazole for active Crohn's disease," Canadian Journal of Gastroenterology, vol. 12, no. 1, pp. 53-56, 1998.

[12] M. Pimentel, W. Morales, K. Chua et al., "Effects of rifaximin treatment and retreatment in nonconstipated IBS subjects," Digestive Diseases and Sciences, vol. 56, no. 7, pp. 2067-2072, 2011.

[13] E. M. M. Quigley, "Therapies aimed at the gut microbiota and inflammation: antibiotics, prebiotics, probiotics, synbiotics, anti-inflammatory therapies," Gastroenterology Clinics of North America, vol. 40, no. 1, pp. 207-222, 2011.

[14] S. Tedelind, F. Westberg, M. Kjerrulf, and A. Vidal, "Antiinflammatory properties of the short-chain fatty acids acetate and propionate: a study with relevance to inflammatory bowel disease," World Journal of Gastroenterology, vol. 13, no. 20, pp. 2826-2832, 2007.

[15] N. Rajendran and D. Kumar, "Role of diet in the management of inflammatory bowel disease," World Journal of Gastroenterology, vol. 16, no. 12, pp. 1442-1448, 2010.

[16] C. Palmer, E. M. Bik, D. B. DiGiulio, D. A. Relman, and P. O. Brown, "Development of the human infant intestinal microbiota," PLoS Biology, vol. 5, no. 7, p. e177, 2007.

[17] P. B. Eckburg, E. M. Bik, C. N. Bernstein et al., "Microbiology: diversity of the human intestinal microbial flora," Science, vol. 308, no. 5728, pp. 1635-1638, 2005.

[18] J. Qin, R. Li, J. Raes et al., "A human gut microbial gene catalogue established by metagenomic sequencing," Nature, vol. 464, no. 7285, pp. 59-65, 2010. 
[19] L. V. Hooper, T. Midwedt, and J. I. Gordon, "How hostmicrobial interactions shape the nutrient environment of the mammalian intestine," Annual Review of Nutrition, vol. 22, pp. 283-307, 2002.

[20] S. Macfarlane, E. Furrie, A. Kennedy, J. H. Cummings, and G. T. Macfarlane, "Mucosal bacteria in ulcerative colitis," British Journal of Nutrition, vol. 93, supplement 1, pp. S67S72, 2005.

[21] S. Macfarlane and G. T. Macfarlane, "Regulation of shortchain fatty acid production," Proceedings of the Nutrition Society, vol. 62, no. 1, pp. 67-72, 2003.

[22] D. J. Morrison, W. G. Mackay, C. A. Edwards, T. Preston, B. Dodson, and L. T. Weaver, "Butyrate production from oligofructose fermentation by the human faecal flora: what is the contribution of extracellular acetate and lactate?" British Journal of Nutrition, vol. 96, no. 3, pp. 570-577, 2006.

[23] S. H. Duncan, P. Louis, and H. J. Flint, "Lactate-utilizing bacteria, isolated from human feces, that produce butyrate as a major fermentation product," Applied and Environmental Microbiology, vol. 70, no. 10, pp. 5810-5817, 2004.

[24] J. H. Cummings and G. T. MacFarlane, "Gastrointestinal effects of prebiotics," British Journal of Nutrition, vol. 87, supplement 2, pp. S145-S151, 2002.

[25] C. Duggan, J. Gannon, and W. Allan Walker, "Protective nutrients and functional foods for the gastrointestinal tract," American Journal of Clinical Nutrition, vol. 75, no. 5, pp. 789$808,2002$.

[26] D. L. Topping and P. M. Clifton, "Short-chain fatty acids and human colonic function: roles of resistant starch and nonstarch polysaccharides," Physiological Reviews, vol. 81, no. 3, pp. 1031-1064, 2001.

[27] I. Sekirov, N. M. Tam, M. Jogova et al., "Antibioticinduced perturbations of the intestinal microbiota alter host susceptibility to enteric infection," Infection and Immunity, vol. 76, no. 10, pp. 4726-4736, 2008.

[28] I. Sekirov and B. B. Finlay, "The role of the intestinal microbiota in enteric infection," Journal of Physiology, vol. 587, no. 17, pp. 4159-4167, 2009.

[29] S. R. Gill, M. Pop, R. T. Deboy et al., "Metagenomic analysis of the human distal gut microbiome," Science, vol. 312, no. 5778, pp. 1355-1359, 2006.

[30] E. S. Klaassens, W. M. De Vos, and E. E. Vaughan, "Metaproteomics approach to study the functionality of the microbiota in the human infant gastrointestinal tract," Applied and Environmental Microbiology, vol. 73, no. 4, pp. 1388-1392, 2007.

[31] P. J. Turnbaugh, R. E. Ley, M. Hamady, C. M. Fraser-Liggett, R. Knight, and J. I. Gordon, "The human microbiome project," Nature, vol. 449, no. 7164, pp. 804-810, 2007.

[32] C. Manichanh, L. Rigottier-Gois, E. Bonnaud et al., "Reduced diversity of faecal microbiota in Crohn's disease revealed by a metagenomic approach," Gut, vol. 55, no. 2, pp. 205-211, 2006.

[33] E. M. M. Quigley, "Germs, gas and the gut; the evolving role of the enteric flora in IBS," American Journal of Gastroenterology, vol. 101, no. 2, pp. 334-335, 2006.

[34] P. J. Turnbaugh, R. E. Ley, M. A. Mahowald, V. Magrini, E. R. Mardis, and J. I. Gordon, "An obesity-associated gut microbiome with increased capacity for energy harvest," Nature, vol. 444, no. 7122, pp. 1027-1031, 2006.

[35] H. Tilg, A. R. Moschen, and A. Kaser, "Obesity and the microbiota," Gastroenterology, vol. 136, no. 5, pp. 1476-1483, 2009.
[36] G. W. Sewell, D. J. Marks, and A. W. Segal, "The immunopathogenesis of Crohn's disease: a three-stage model," Current Opinion in Immunology, vol. 21, no. 5, pp. 506-513, 2009.

[37] L. D. McVay, S. A. Keilbaugh, T. M. H. Wong et al., "Absence of bacterially induced RELM $\beta$ reduces injury in the dextran sodium sulfate model of colitis," Journal of Clinical Investigation, vol. 116, no. 11, pp. 2914-2923, 2006.

[38] M. A. McGuckin, R. Eri, L. A. Simms, T. H. J. Florin, and G. Radford-Smith, "Intestinal barrier dysfunction in inflammatory bowel diseases," Inflammatory Bowel Diseases, vol. 15, no. 1, pp. 100-113, 2009.

[39] C. Abraham and J. H. Cho, "Functional consequences of NOD2 (CARD15) mutations," Inflammatory Bowel Diseases, vol. 12, no. 7, pp. 641-650, 2006.

[40] M. Hedl, J. Li, J. H. Cho, and C. Abraham, "Chronic stimulation of Nod2 mediates tolerance to bacterial products," Proceedings of the National Academy of Sciences of the United States of America, vol. 104, no. 49, pp. 19440-19445, 2007.

[41] S. Nell, S. Suerbaum, and C. Josenhans, "The impact of the microbiota on the pathogenesis of IBD: lessons from mouse infection models," Nature Reviews Microbiology, vol. 8, no. 8, pp. 564-577, 2010.

[42] D. J. Marks, M. W. Harbord, R. MacAllister et al., "Defective acute inflammation in Crohn's disease: a clinical investigation," The Lancet, vol. 367, no. 9511, pp. 668-678, 2006.

[43] A. M. Smith, F. Z. Rahman, B. Hayee et al., "Disordered macrophage cytokine secretion underlies impaired acute inflammation and bacterial clearance in Crohn's disease," Journal of Experimental Medicine, vol. 206, no. 9, pp. 18831897, 2009.

[44] A. W. Segal and G. Loewi, "Neutrophil dysfunction in Crohn's disease," The Lancet, vol. 2, no. 7979, pp. 219-221, 1976.

[45] S. Danese and C. Fiocchi, "Ulcerative colitis," The New England Journal of Medicine, vol. 365, no. 18, pp. 1713-1725, 2011.

[46] J. Wehkamp, K. Fellermann, and E. F. Stange, "Human defensins in Crohn's disease: a molecular link to mucosal barrier dysfunction," Chemical Immunology and Allergy, vol. 86, pp. 42-54, 2005.

[47] L. A. Simms, J. D. Doecke, M. D. Walsh, N. Huang, E. V. Fowler, and G. L. Radford-Smith, "Reduced $\alpha$-defensin expression is associated with inflammation and not NOD2 mutation status in ileal Crohn's disease," Gut, vol. 57, no. 7, pp. 903-910, 2008.

[48] S. Schmechel, A. Konrad, J. Diegelmann et al., "Linking genetic susceptibility to Crohn's disease with Th17 cell function: IL-22 serum levels are increased in Crohn's disease and correlate with disease activity and IL23R genotype status," Inflammatory Bowel Diseases, vol. 14, no. 2, pp. 204212, 2008.

[49] T. Kobayashi, S. Okamoto, T. Hisamatsu et al., "IL23 differentially regulates the Th1/Th17 balance in ulcerative colitis and Crohn's disease," Gut, vol. 57, no. 12, pp. 16821689,2008

[50] C. Abraham and J. H. Cho, "Inflammatory bowel disease," New England Journal of Medicine, vol. 361, no. 21, pp. 20662078, 2009.

[51] D. C. Baumgart and S. R. Carding, "Inflammatory bowel disease: cause and immunobiology," The Lancet, vol. 369, no. 9573, pp. 1627-1640, 2007.

[52] D. Artis, "Epithelial-cell recognition of commensal bacteria and maintenance of immune homeostasis in the gut," 
Nature Reviews Immunology, vol. 8, no. 6, pp. 411-420, 2008.

[53] I. I. Ivanov and D. R. Littman, "Modulation of immune homeostasis by commensal bacteria," Current Opinion in Microbiology, vol. 14, no. 1, pp. 106-114, 2011.

[54] J. L. Round and S. K. Mazmanian, "The gut microbiota shapes intestinal immune responses during health and disease," Nature Reviews Immunology, vol. 9, no. 5, pp. 313323, 2009.

[55] A. S. Neish, "Microbes in gastrointestinal health and disease," Gastroenterology, vol. 136, no. 1, pp. 65-80, 2009.

[56] R. B. Sartor and M. Muehlbauer, "Microbial host interactions in IBD: implications for pathogenesis and therapy," Current Gastroenterology Reports, vol. 9, no. 6, pp. 497-507, 2007.

[57] C. P. Tamboli, C. Neut, P. Desreumaux, and J. F. Colombel, "Dysbiosis in inflammatory bowel disease," Gut, vol. 53, no. 1, pp. 1-4, 2004.

[58] P. D. Scanlan, F. Shanahan, C. O'Mahony, and J. R. Marchesi, "Culture-independent analyses of temporal variation of the dominant fecal microbiota and targeted bacterial subgroups in Crohn's disease," Journal of Clinical Microbiology, vol. 44, no. 11, pp. 3980-3988, 2006.

[59] D. N. Frank, A. L. S. Amand, R. A. Feldman, E. C. Boedeker, N. Harpaz, and N. R. Pace, "Molecular-phylogenetic characterization of microbial community imbalances in human inflammatory bowel diseases," Proceedings of the National Academy of Sciences of the United States of America, vol. 104, no. 34, pp. 13780-13785, 2007.

[60] C. Favier, C. Neut, C. Mizon, A. Cortot, J. F. Colombel, and J. Mizon, "Fecal $\beta$-D-galactosidase production and Bifidobacteria are decreased in Crohn's disease," Digestive Diseases and Sciences, vol. 42, no. 4, pp. 817-822, 1997.

[61] P. B. Eckburg and D. A. Relman, "The role of microbes in Crohn's disease," Clinical Infectious Diseases, vol. 44, no. 2, pp. 256-262, 2007.

[62] A. Swidsinski, V. Loening-Baucke, M. Vaneechoutte, and Y. Doerffel, "Active Crohn's disease and ulcerative colitis can be specifically diagnosed and monitored based on the biostructure of the fecal flora," Inflammatory Bowel Diseases, vol. 14, no. 2, pp. 147-161, 2008.

[63] A. Suau, V. Rochet, A. Sghir et al., "Fusobacterium prausnitzii and related species represent a dominant group within the human fecal flora," Systematic and Applied Microbiology, vol. 24, no. 1, pp. 139-145, 2001.

[64] A. Swidsinski, V. Loening-Baucke, H. Lochs, and L. P. Hale, "Spatial organization of bacterial flora in normal and inflamed intestine: a fluorescence in situ hybridization study in mice," World Journal of Gastroenterology, vol. 11, no. 8, pp. 1131-1140, 2005.

[65] H. M. Martin, B. J. Campbell, C. A. Hart et al., "Enhanced Escherichia coli adherence and invasion in Crohn's disease and colon cancer," Gastroenterology, vol. 127, no. 1, pp. 8093, 2004.

[66] M. H. Giaffer, C. D. Holdsworth, and B. I. Duerden, "Virulence properties of Escherichia coli strains isolated from patients with inflammatory bowel disease," Gut, vol. 33, no. 5, pp. 646-650, 1992.

[67] N. Barnich, F. A. Carvalho, A. L. Glasser et al., "CEACAM6 acts as a receptor for adherent-invasive E. coli, supporting ileal mucosa colonization in Crohn disease," Journal of Clinical Investigation, vol. 117, no. 6, pp. 1566-1574, 2007.

[68] B. P. Willing, J. Dicksved, J. Halfvarson et al., "A pyrosequencing study in twins shows that gastrointestinal microbial profiles vary with inflammatory bowel disease phenotypes," Gastroenterology, vol. 139, no. 6, pp. 1844-1854.e1, 2010.

[69] B. Stecher, S. Chaffron, R. Käppeli et al., "Like will to like: abundances of closely related species can predict susceptibility to intestinal colonization by pathogenic and commensal bacteria," PLoS Pathogens, vol. 6, no. 1, Article ID e1000711, 2010.

[70] A. Macpherson, U. Y. Khoo, I. Forgacs, J. Philpott-Howard, and I. Bjarnason, "Mucosal antibodies in inflammatory bowel disease are directed against intestinal bacteria," Gut, vol. 38, no. 3, pp. 365-375, 1996.

[71] C. O. Elson, "Commensal bacteria as targets in Crohn's disease," Gastroenterology, vol. 119, no. 1, pp. 254-257, 2000.

[72] R. Soret, J. Chevalier, P. De Coppet et al., "Short-chain fatty acids regulate the enteric neurons and control gastrointestinal motility in rats," Gastroenterology, vol. 138, no. 5, pp. 1772-1782.e4, 2010.

[73] H. M. Hamer, D. M. A. E. Jonkers, A. Bast et al., "Butyrate modulates oxidative stress in the colonic mucosa of healthy humans," Clinical Nutrition, vol. 28, no. 1, pp. 88-93, 2009.

[74] S. A. L. W. Vanhoutvin, F. J. Troost, H. M. Hamer et al., "Butyrate-induced transcriptional changes in human colonic mucosa," PLoS One, vol. 4, no. 8, Article ID e6759, 2009.

[75] K. Daly and S. P. Shirazi-Beechey, "Microarray analysis of butyrate regulated genes in colonic epithelial cells," DNA and Cell Biology, vol. 25, no. 1, pp. 49-62, 2006.

[76] J. R. Davie, "Inhibition of histone deacetylase activity by butyrate," Journal of Nutrition, vol. 133, no. 7, pp. 2485S2493S, 2003.

[77] J. P. Segain, J. P. Galmiche, D. Raingeard De La Blétière et al., "Butyrate inhibits inflammatory responses through $\mathrm{NF} \kappa \mathrm{B}$ inhibition: implications for Crohn's disease," Gut, vol. 47, no. 3, pp. 397-403, 2000.

[78] C. H. Leung, W. Lam, D. L. Ma, E. A. Gullen, and Y. C. Cheng, "Butyrate mediates nucleotide-binding and oligomerisation domain (NOD) 2-dependent mucosal immune responses against peptidoglycan," European Journal of Immunology, vol. 39, no. 12, pp. 3529-3537, 2009.

[79] M. Stempelj, M. Kedinger, L. Augenlicht, and L. Klampfer, "Essential role of the JAK/STAT1 signaling pathway in the expression of inducible nitric-oxide synthase in intestinal epithelial cells and its regulation by butyrate," Journal of Biological Chemistry, vol. 282, no. 13, pp. 9797-9804, 2007.

[80] S. Saegusa, M. Totsuka, S. Kaminogawa, and T. Hosoi, "Candida albicans and Saccharomyces cerevisiae induce interleukin-8 production from intestinal epithelial-like Caco-2 cells in the presence of butyric acid," FEMS Immunology and Medical Microbiology, vol. 41, no. 3, pp. 227-235, 2004.

[81] M. Schwab, V. Reynders, S. Loitsch, D. Steinhilber, J. Stein, and O. Schröder, "Involvement of different nuclear hormone receptors in butyrate-mediated inhibition of inducible $\mathrm{NF} \kappa \mathrm{B}$ signalling," Molecular Immunology, vol. 44, no. 15, pp. 36253632, 2007.

[82] M. Kinoshita, Y. Suzuki, and Y. Saito, "Butyrate reduces colonic paracellular permeability by enhancing PPAR $\gamma$ activation," Biochemical and Biophysical Research Communications, vol. 293, no. 2, pp. 827-831, 2002.

[83] U. Böcker, O. Yezerskyy, P. Feick et al., "Responsiveness of intestinal epithelial cell lines to lipopolysaccharide is correlated with Toll-like receptor 4 but not Toll-like receptor 2 or CD14 expression," International Journal of Colorectal Disease, vol. 18, no. 1, pp. 25-32, 2003. 
[84] H. Chirakkal, S. H. Leech, K. E. Brookes, A. L. Prais, J. S. Waby, and B. M. Corfe, "Upregulation of BAK by butyrate in the colon is associated with increased Sp3 binding," Oncogene, vol. 25, no. 54, pp. 7192-7200, 2006.

[85] D. Zgouras, A. Wächtershäuser, D. Frings, and J. Stein, "Butyrate impairs intestinal tumor cell-induced angiogenesis by inhibiting HIF- $1 \alpha$ nuclear translocation," Biochemical and Biophysical Research Communications, vol. 300, no. 4, pp. 832-838, 2003.

[86] J. Rodríguez-Salvador, C. Armas-Pineda, M. PerezpeñaDiazconti et al., "Effect of sodium butyrate on pro-matrix metalloproteinase- 9 and -2 differential secretion in pediatric tumors and cell lines," Journal of Experimental and Clinical Cancer Research, vol. 24, no. 3, pp. 463-473, 2005.

[87] J. M. Mariadason, D. H. Barkla, and P. R. Gibson, "Effect of short-chain fatty acids on paracellular permeability in Caco- 2 intestinal epithelium model," American Journal of Physiology, vol. 272, no. 4, pp. G705-G712, 1997.

[88] L. Peng, Z. He, W. Chen, I. R. Holzman, and J. Lin, "Effects of butyrate on intestinal barrier function in a caco-2 cell monolayer model of intestinal barrier," Pediatric Research, vol. 61, no. 1, pp. 37-41, 2007.

[89] A. J. Wilson and P. R. Gibson, "Short-chain fatty acids promote the migration of colonic epithelial cells in vitro," Gastroenterology, vol. 113, no. 2, pp. 487-496, 1997.

[90] S. K. Mazmanian, J. L. Round, and D. L. Kasper, "A microbial symbiosis factor prevents intestinal inflammatory disease," Nature, vol. 453, no. 7195, pp. 620-625, 2008.

[91] O. Kanauchi, T. Suga, M. Tochihara et al., "Treatment of ulcerative colitis by feeding with germinated barley foodstuff: first report of a multicenter open control trial," Journal of Gastroenterology, vol. 37, supplement 14, pp. 67-72, 2002.

[92] J. M. Harig, K. H. Soergel, R. A. Komorowski, and C. M. Wood, "Treatment of diversion colitis with short-chain-fatty acid irrigation," New England Journal of Medicine, vol. 320, no. 1, pp. 23-28, 1989.

[93] H. Lührs, T. Gerke, J. G. Müller et al., "Butyrate inhibits NF$\kappa \mathrm{B}$ activation in lamina propria macrophages of patients with ulcerative colitis," Scandinavian Journal of Gastroenterology, vol. 37, no. 4, pp. 458-466, 2002.

[94] E. Le Poul, C. Loison, S. Struyf et al., "Functional characterization of human receptors for short chain fatty acids and their role in polymorphonuclear cell activation," Journal of Biological Chemistry, vol. 278, no. 28, pp. 25481-25489, 2003.

[95] K. M. Maslowski, A. T. Vieira, A. Ng et al., "Regulation of inflammatory responses by gut microbiota and chemoattractant receptor GPR43," Nature, vol. 461, no. 7268, pp. 1282 1286, 2009.

[96] S. Fukuda, H. Toh, K. Hase et al., "Bifidobacteria can protect from enteropathogenic infection through production of acetate," Nature, vol. 469, no. 7331, pp. 543-549, 2011.

[97] P. R. Gibson, "The intracellular target of butyrate's actions: HDAC or HDON'T?" Gut, vol. 46, no. 4, pp. 447-448, 2000.

[98] M. S. Inan, R. J. Rasoulpour, L. Yin, A. K. Hubbard, D. W. Rosenberg, and C. Giardina, "The luminal short-chain fatty acid butyrate modulates NF- $\kappa$ B activity in a human colonic epithelial cell line," Gastroenterology, vol. 118, no. 4, pp. 724734,2000

[99] R. F. Place, E. J. Noonan, and C. Giardina, "HDAC inhibition prevents NF- $\kappa \mathrm{B}$ activation by suppressing proteasome activity: down-regulation of proteasome subunit expression stabilizes $\mathrm{I} \kappa \mathrm{B} \alpha$," Biochemical Pharmacology, vol. 70, no. 3, pp. 394-406, 2005.
[100] R. D. Fusunyan, J. J. Quinn, M. Fujimoto, R. P. MacDermott, and I. R. Sanderson, "Butyrate switches the pattern of chemokine secretion by intestinal epithelial cells through histone acetylation," Molecular Medicine, vol. 5, no. 9, pp. 631-640, 1999.

[101] M. Weng, W. A. Walker, and I. R. Sanderson, "Butyrate regulates the expression of pathogen-triggered IL-8 in intestinal epithelia," Pediatric Research, vol. 62, no. 5, pp. 542-546, 2007.

[102] U. Böcker, T. Nebe, F. Herweck et al., "Butyrate modulates intestinal epithelial cell-mediated neutrophil migration," Clinical and Experimental Immunology, vol. 131, no. 1, pp. 53-60, 2003.

[103] S. Toden, A. R. Bird, D. L. Topping, and M. A. Conlon, "Dosedependent reduction of dietary protein-induced colonocyte DNA damage by resistant starch in rats correlates more highly with caecal butyrate than with other short chain fatty acids," Cancer Biology and Therapy, vol. 6, no. 2, pp. 253-258, 2007.

[104] P. Rosignolli, R. Fabianni, A. De Bartolomeo et al., "Protective activity of butyrate on hydrogen peroxide-induced DNA damage in isolated human colonocytes and HT29 tumour cells," Carcinogenesis, vol. 22, no. 10, pp. 1675-1680, 2001.

[105] J. J. Malago, J. F. J. G. Koninkx, P. C. J. Tooten, E. A. Van Liere, and J. E. Van Dijk, "Anti-inflammatory properties of heat shock protein 70 and butyrate on Salmonellainduced interleukin-8 secretion in enterocyte-like Caco-2 cells," Clinical and Experimental Immunology, vol. 141, no. 1, pp. 62-71, 2005.

[106] A. Venkatraman, B. S. Ramakrishna, R. V. Shaji, N. S. N. Kumar, A. Pulimood, and S. Patra, "Amelioration of dextran sulfate colitis by butyrate: role of heat shock protein 70 and NF- $\kappa \mathrm{B}$," American Journal of Physiology, vol. 285, no. 1, pp. G177-G184, 2003.

[107] L. E. M. Willemsen, M. A. Koetsier, S. J. H. Van Deventer, and E. A. F. Van Tol, "Short chain fatty acids stimulate epithelial mucin 2 expression through differential effects on prostaglandin $\mathrm{E}_{1}$ and $\mathrm{E}_{2}$ production by intestinal myofibroblasts," Gut, vol. 52, no. 10, pp. 1442-1447, 2003.

[108] E. Gaudier, A. Jarry, H. M. Blottière et al., "Butyrate specifically modulates MUC gene expression in intestinal epithelial goblet cells deprived of glucose," American Journal of Physiology, vol. 287, no. 6, pp. G1168-G1174, 2004.

[109] C. Moehle, N. Ackermann, T. Langmann et al., "Aberrant intestinal expression and allelic variants of mucin genes associated with inflammatory bowel disease," Journal of Molecular Medicine, vol. 84, no. 12, pp. 1055-1066, 2006.

[110] A. Barcelo, J. Claustre, F. Moro, J. A. Chayvialle, J. C. Cuber, and P. Plaisancié, "Mucin secretion is modulated by luminal factors in the isolated vascularly perfused rat colon," Gut, vol. 46, no. 2, pp. 218-224, 2000.

[111] J. Schauber, C. Svanholm, S. Termén et al., "Expression of the cathelicidin LL-37 is modulated by short chain fatty acids in colonocytes: relevance of signalling pathways," Gut, vol. 52, no. 5, pp. 735-741, 2003.

[112] K. Kato, Y. Ishii, S. Mizuno et al., "Usefulness of rectally administering $\left[1-{ }^{13} \mathrm{C}\right]$-butyrate for breath test in patients with active and quiescent ulcerative colitis," Scandinavian Journal of Gastroenterology, vol. 42, no. 2, pp. 207-214, 2007.

[113] S. Nancey, D. Moussata, I. Graber, S. Claudel, J. C. Saurin, and B. Flourié, "Tumor necrosis factor $\alpha$ reduces butyrate oxidation in vitro in human colonic mucosa: a link from inflammatory process to mucosal damage?" Inflammatory Bowel Diseases, vol. 11, no. 6, pp. 559-566, 2005. 
[114] P. Marteau, "Probiotics, prebiotics, synbiotics: ecological treatment for inflammatory bowel disease?" Gut, vol. 55, no. 12, pp. 1692-1693, 2006.

[115] H. M. Hamer, D. Jonkers, K. Venema, S. Vanhoutvin, F. J. Troost, and R. J. Brummer, "Review article: the role of butyrate on colonic function," Alimentary Pharmacology and Therapeutics, vol. 27, no. 2, pp. 104-119, 2008.

[116] I. R. Sanderson, "Dietary modulation of GALT," Journal of Nutrition, vol. 137, no. 11, pp. 2557S-2562S, 2007.

[117] W. Scheppach and F. Weiler, "The butyrate story: old wine in new bottles?" Current Opinion in Clinical Nutrition and Metabolic Care, vol. 7, no. 5, pp. 563-567, 2004.

[118] P. Vernia, M. Di Camillo, V. Marinaro, and R. Caprilli, "Effect of predominant methanogenic flora on the outcome of lactose breath test in irritable bowel syndrome patients," European Journal of Clinical Nutrition, vol. 57, no. 9, pp. 1116-1119, 2003.

[119] W. Scheppach, H. Sommer, T. Kirchner et al., "Effect of butyrate enemas on the colonic mucosa in distal ulcerative colitis," Gastroenterology, vol. 103, no. 1, pp. 51-56, 1992.

[120] J. M. W. Wong, R. De Souza, C. W. C. Kendall, A. Emam, and D. J. A. Jenkins, "Colonic health: fermentation and short chain fatty acids," Journal of Clinical Gastroenterology, vol. 40, no. 3, pp. 235-243, 2006.

[121] A. H. Steinhart, T. Hiruki, A. Brzezinski, and J. P. Baker, "Treatment of left-sided ulcerative colitis with butyrate enemas: a controlled trial," Alimentary Pharmacology and Therapeutics, vol. 10, no. 5, pp. 729-736, 1996.

[122] R. I. Breuer, K. H. Soergel, B. A. Lashner et al., "Short chain fatty acid rectal irrigation for left-sided ulcerative colitis: a randomised, placebo controlled trial," Gut, vol. 40, no. 4, pp. 485-491, 1997.

[123] R. J. Xavier and D. K. Podolsky, "Unravelling the pathogenesis of inflammatory bowel disease," Nature, vol. 448, no. 7152, pp. 427-434, 2007.

[124] P. L. Lakatos, S. Fischer, L. Lakatos, I. Gal, and J. Papp, "Current concept on the pathogenesis of inflammatory bowel disease-crosstalk between genetic and microbial factors: pathogenic bacteria and altered bacterial sensing or changes in mucosal integrity take "tool"?" World Journal of Gastroenterology, vol. 12, no. 12, pp. 1829-1841, 2006.

[125] F. Z. Rahman, D. J. B. Marks, B. H. Hayee, A. M. Smith, S. L. Bloom, and A. W. Segal, "Phagocyte dysfunction and inflammatory bowel disease," Inflammatory Bowel Diseases, vol. 14, no. 10, pp. 1443-1452, 2008.

[126] J. R. Korzenik and B. K. Dieckgraefe, "Is Crohn's disease an immunodeficiency? A hypothesis suggesting possible early events in the pathogenesis of Crohn's disease," Digestive Diseases and Sciences, vol. 45, no. 6, pp. 1121-1129, 2000.

[127] J. R. Turner, "Molecular basis of epithelial barrier regulation: from basic mechanisms to clinical application," American Journal of Pathology, vol. 169, no. 6, pp. 1901-1909, 2006.

[128] M. Bruewer, A. Luegering, T. Kucharzik et al., "Proinflammatory cytokines disrupt epithelial barrier function by apoptosis-independent mechanisms," Journal of Immunology, vol. 171, no. 11, pp. 6164-6172, 2003.

[129] S. Dahan, G. Roda, D. Pinn et al., "Epithelial: lamina propria lymphocyte interactions promote epithelial cell differentiation," Gastroenterology, vol. 134, no. 1, pp. 192-203, 2008.

[130] J. Berkes, V. K. Viswanathan, S. D. Savkovic, and G. Hecht, "Intestinal epithelial responses to enteric pathogens: effects on the tight junction barrier, ion transport, and inflammation," Gut, vol. 52, no. 3, pp. 439-451, 2003.
[131] R. K. Russell and J. Satsangi, "IBD: a family affair," Best Practice and Research, vol. 18, no. 3, pp. 525-539, 2004.

[132] N. Mahmud and D. G. Weir, "The urban diet and Crohn's disease: is there a relationship?" European Journal of Gastroenterology and Hepatology, vol. 13, no. 2, pp. 93-95, 2001.

[133] A. Schirbel and C. Fiocchi, "Inflammatory bowel disease: established and evolving considerations on its etiopathogenesis and therapy," Journal of Digestive Diseases, vol. 11, no. 5, pp. 266-276, 2010.

[134] L. Mayer, "Evolving paradigms in the pathogenesis of IBD," Journal of Gastroenterology, vol. 45, no. 1, pp. 9-16, 2010.

[135] T. Gardenbroek, E. Eshuis, C. Ponsioen, D. Ubbink, G. D'Haens, and W. Bemelman, "The effect of appendectomy on the course of ulcerative colitis: a systematic review," Colorectal Disease. In press.

[136] A. Hviid, H. Svanström, and M. Frisch, "Antibiotic use and inflammatory bowel diseases in childhood," Gut, vol. 60, no. 1, pp. 49-54, 2011.

[137] N. Inohara, Y. Ogura, A. Fontalba et al., "Host recognition of bacterial muramyl dipeptide mediated through NOD2: implications for Crohn's disease," Journal of Biological Chemistry, vol. 278, no. 8, pp. 5509-5512, 2003.

[138] K. S. Kobayashi, M. Chamaillard, Y. Ogura et al., "Nod2dependent regulation of innate and adaptive immunity in the intestinal tract," Science, vol. 307, no. 5710, pp. 731-734, 2005.

[139] J. P. Hugot, M. Chamaillard, H. Zouali et al., "Association of NOD2 leucine-rich repeat variants with susceptibility to Crohn's disease," Nature, vol. 411, no. 6837, pp. 599-603, 2001.

[140] Y. Ogura, D. K. Bonen, N. Inohara et al., "A frameshift mutation in NOD2 associated with susceptibility to Crohn's disease," Nature, vol. 411, no. 6837, pp. 603-606, 2001.

[141] C. Q. Zheng, G. Z. Hu, Z. S. Zeng, L. J. Lin, and G. G. $\mathrm{Gu}$, "Progress in searching for susceptibility gene for inflammatory bowel disease by positional cloning," World Journal of Gastroenterology, vol. 9, no. 8, pp. 1646-1656, 2003.

[142] D. K. Bonen, Y. Ogura, D. L. Nicolae et al., "Crohn's diseaseassociated NOD2 variants share a signaling defect in response to lipopolysaccharide and peptidoglycan," Gastroenterology, vol. 124, no. 1, pp. 140-146, 2003.

[143] J. Li, T. Moran, E. Swanson et al., "Regulation of IL-8 and IL$1 \beta$ expression in Crohn's disease associated NOD2/CARD15 mutations," Human Molecular Genetics, vol. 13, no. 16, pp. 1715-1725, 2004.

[144] S. Lesage, H. Zouali, J. P. Cézard et al., "CARD15/NOD2 mutational analysis and genotype-phenotype correlation in 612 patients with inflammatory bowel disease," American Journal of Human Genetics, vol. 70, no. 4, pp. 845-857, 2002.

[145] J. P. Hugot, I. Zaccaria, J. Cavanaugh et al., "Prevalence of CARD15/NOD2 mutations in Caucasian healthy people," American Journal of Gastroenterology, vol. 102, no. 6, pp. 1259-1267, 2007.

[146] N. Kamada, T. Hisamatsu, S. Okamoto et al., "Unique CD14 intestinal macrophages contribute to the pathogenesis of Crohn disease via IL-23/IFN- $\gamma$ axis," Journal of Clinical Investigation, vol. 118, no. 6, pp. 2269-2280, 2008.

[147] J. M. Marinis, C. R. Homer, C. McDonald, and D. W. Abbott, "A novel motif in the Crohn's disease susceptibility protein, NOD2, allows TRAF4 to down-regulate innate immune responses," Journal of Biological Chemistry, vol. 286, no. 3, pp. 1938-1950, 2011.

[148] K. Cadwell, T. S. Stappenbeck, and H. W. Virgin, "Role of autophagy and autophagy genes in inflammatory bowel 
disease," Current Topics in Microbiology and Immunology, vol. 335, no. 1, pp. 141-167, 2009.

[149] D. Schmid and C. Münz, "Innate and adaptive immunity through autophagy," Immunity, vol. 27, no. 1, pp. 11-21, 2007.

[150] J. D. Rioux, R. J. Xavier, K. D. Taylor et al., "Genome-wide association study identifies new susceptibility loci for Crohn disease and implicates autophagy in disease pathogenesis," Nature Genetics, vol. 39, no. 5, pp. 596-604, 2007.

[151] M. Parkes, J. C. Barrett, N. J. Prescott et al., "Sequence variants in the autophagy gene IRGM and multiple other replicating loci contribute to Crohn's disease susceptibility," Nature Genetics, vol. 39, no. 7, pp. 830-832, 2007.

[152] J. Hampe, A. Franke, P. Rosenstiel et al., "A genomewide association scan of nonsynonymous SNPs identifies a susceptibility variant for Crohn disease in ATG16L1," Nature Genetics, vol. 39, no. 2, pp. 207-211, 2007.

[153] S. A. McCarroll, A. Huett, P. Kuballa et al., "Deletion polymorphism upstream of IRGM associated with altered IRGM expression and Crohn's disease," Nature Genetics, vol. 40, no. 9, pp. 1107-1112, 2008.

[154] E. R. Nimmo, C. Stevens, A. M. Phillips et al., "TLE1 modifies the effects of NOD2 in the pathogenesis of Crohn's disease," Gastroenterology, vol. 141, no. 3, pp. 972-981.e2, 2011.

[155] T. T. Wang, B. Dabbas, D. Laperriere et al., "Direct and indirect induction by 1,25-dihydroxyvitamin $\mathrm{D}_{3}$ of the NOD2/CARD15-defensin $\beta 2$ innate immune pathway defective in crohn disease," Journal of Biological Chemistry, vol. 285, no. 4, pp. 2227-2231, 2010.

[156] S. Ishihara, M. M. Aziz, T. Yuki, H. Kazumori, and Y. Kinoshita, "Inflammatory bowel disease: review from the aspect of genetics," Journal of Gastroenterology, vol. 44, no. 11, pp. 1097-1108, 2009.

[157] J. C. Barrett, S. Hansoul, D. L. Nicolae et al., "Genome-wide association defines more than 30 distinct susceptibility loci for Crohn's disease," Nature Genetics, vol. 40, no. 8, pp. 955962, 2008.

[158] A. Swidsinski, A. Ladhoff, A. Pernthaler et al., "Mucosal flora in inflammatory bowel disease," Gastroenterology, vol. 122, no. 1, pp. 44-54, 2002.

[159] S. J. Ott, M. Musfeldt, D. F. Wenderoth et al., "Reduction in diversity of the colonic mucosa associated bacterial microflora in patients with active inflammatory bowel disease," Gut, vol. 53, no. 5, pp. 685-693, 2004.

[160] P. Eadala, S. B. Matthews, J. P. Waud, J. T. Green, and A. K. Campbell, "Association of lactose sensitivity with inflammatory bowel disease-demonstrated by analysis of genetic polymorphism, breath gases and symptoms," Alimentary Pharmacology and Therapeutics, vol. 34, no. 7, pp. 735-746, 2011.

[161] M. Camilleri, I. Busciglio, P. Carlson et al., "Candidate genes and sensory functions in health and irritable bowel syndrome," American Journal of Physiology, vol. 295, no. 2, pp. G219-G225, 2008.

[162] S. Fukudo and M. Kanazawa, "Gene, environment, and brain gut interactions in irritable bowel syndrome," Journal of gastroenterology and hepatology, vol. 26, pp. 110-115, 2011.

[163] T. S. King, M. Elia, and J. O. Hunter, "Abnormal colonic fermentation in irritable bowel syndrome," The Lancet, vol. 352, no. 9135, pp. 1187-1189, 1998.

[164] K. J. Lee and J. Tack, "Altered intestinal microbiota in irritable bowel syndrome," Neurogastroenterology and Motility, vol. 22, no. 5, pp. 493-498, 2010.
[165] L. O’Mahony, J. Mccarthy, P. Kelly et al., "Lactobacillus and Bifidobacterium in irritable bowel syndrome: symptom responses and relationship to cytokine profiles," Gastroenterology, vol. 128, no. 3, pp. 541-551, 2005.

[166] A. P. Weston, W. L. Biddle, P. S. Bhatia, and P. B. Miner, "Terminal ileal mucosal mast cells in irritable bowel syndrome," Digestive Diseases and Sciences, vol. 38, no. 9, pp. 1590-1595, 1993.

[167] G. R. Locke, A. R. Zinsmeister, N. J. Talley, S. L. Fett, and L. J. Melton, "Risk factors for irritable bowel syndrome: role of analgesics and food sensitivities," American Journal of Gastroenterology, vol. 95, no. 1, pp. 157-165, 2000.

[168] M. Simrén, A. Månsson, A. M. Langkilde et al., "Food-related gastrointestinal symptoms in the irritable bowel syndrome," Digestion, vol. 63, no. 2, pp. 108-115, 2001.

[169] S. J. Shepherd, F. C. Parker, J. G. Muir, and P. R. Gibson, "Dietary triggers of abdominal symptoms in patients with irritable bowel syndrome: randomized placebo-controlled evidence," Clinical Gastroenterology and Hepatology, vol. 6, no. 7, pp. 765-771, 2008.

[170] F. Fernández-Bañares, M. Rosinach, M. Esteve, M. Forné, J. C. Espinós, and J. Maria Viver, "Sugar malabsorption in functional abdominal bloating: a pilot study on the longterm effect of dietary treatment," Clinical Nutrition, vol. 25, no. 5, pp. 824-831, 2006.

[171] D. A. Drossman, L. Chang, N. Bellamy et al., "Severity in irritable bowel syndrome: a rome foundation working team report," American Journal of Gastroenterology, vol. 106, no. 10, pp. 1749-1759, 2011.

[172] A. Belluzzi, C. Brignola, M. Campieri, A. Pera, S. Boschi, and M. Miglioli, "Effect of an enteric-coated fish-oil preparation on relapses in Crohn's disease," New England Journal of Medicine, vol. 334, no. 24, pp. 1557-1560, 1996.

[173] T. Tsujikawa, J. Satoh, K. Uda et al., "Clinical importance of n-3 fatty acid-rich diet and nutritional education for the maintenance of remission in Crohn's disease," Journal of Gastroenterology, vol. 35, no. 2, pp. 99-104, 2000.

[174] B. M. Popkin and S. J. Nielsen, "The sweetening of the world's diet," Obesity Research, vol. 11, no. 11, pp. 1325-1332, 2003.

[175] S. M. Skoog, A. E. Bharucha, M. Camilleri, D. D. Burton, and A. R. Zinsmeister, "Effects of an osmotically active agent on colonic transit," Neurogastroenterology and Motility, vol. 18, no. 4, pp. 300-306, 2006.

[176] P. R. Gibson and S. J. Shepherd, "Evidence-based dietary management of functional gastrointestinal symptoms: the FODMAP approach," Journal of Gastroenterology and Hepatology, vol. 25, no. 2, pp. 252-258, 2010.

[177] J. Serra, A. Villoria, F. Azpiroz et al., "Impaired intestinal gas propulsion in manometrically proven dysmotility and in irritable bowel syndrome," Neurogastroenterology and Motility, vol. 22, no. 4, pp. 401-406, 2010.

[178] J. S. Barrett, R. B. Gearry, J. G. Muir et al., "Dietary poorly absorbed, short-chain carbohydrates increase delivery of water and fermentable substrates to the proximal colon," Alimentary Pharmacology and Therapeutics, vol. 31, no. 8, pp. 874-882, 2010.

[179] A. Ropert, C. Cherbut, C. Roze et al., "Colonic fermentation and proximal gastric tone in humans," Gastroenterology, vol. 111, no. 2, pp. 289-296, 1996.

[180] S. P. Sheikh, "Neuropeptide Y and peptide YY: major modulators of gastrointestinal blood flow and function," American Journal of Physiology, vol. 261, no. 5, pp. G701G715, 1991. 
[181] J. R. Thornton, P. M. Emmett, and K. W. Heaton, "Diet and Crohn's disease: characteristics of the pre-illness diet," British Medical Journal, vol. 2, no. 6193, pp. 762-764, 1979.

[182] K. Silkoff, A. Hallak, L. Yegena et al., "Consumption of refined carbohydrate by patients with Crohn's disease in TelAviv-Yafo," Postgraduate Medical Journal, vol. 56, no. 662, pp. 842-846, 1980.

[183] G. Jarnerot, I. Jarnmark, and K. Nilsson, "Consumption of refined sugar by patients with Crohn's disease, ulcerative colitis, or irritable bowel syndrome," Scandinavian Journal of Gastroenterology, vol. 18, no. 8, pp. 999-1002, 1983.

[184] B. Katschinski, R. F. A. Logan, M. Edmond, and M. J. S. Langman, "Smoking and sugar intake are separate but interactive risk factors in Crohn's disease," Gut, vol. 29, no. 9, pp. 1202-1206, 1988.

[185] A. Tragnone, D. Valpiani, F. Miglio et al., "Dietary habits as risk factors for inflammatory bowel disease," European Journal of Gastroenterology and Hepatology, vol. 7, no. 1, pp. 47-51, 1995.

[186] A. Sonnenberg, "Geograhic and temporal variations of sugar and margarine consumption in relation to Crohn's disease," Digestion, vol. 41, no. 3, pp. 161-171, 1988.

[187] I. Koutroubakis, O. N. Manousos, S. G. M. Meuwissen, and A. S. Pena, "Environmental risk factors in inflammatory bowel disease," Hepato-Gastroenterology, vol. 43, no. 8, pp. 381-393, 1996.

[188] T. Yamamoto, M. Nakahigashi, and A. R. Saniabadi, "Review article: diet and inflammatory bowel disease-epidemiology and treatment," Alimentary Pharmacology and Therapeutics, vol. 30, no. 2, pp. 99-112, 2009.

[189] A. L. Henderson, W. W. Cao, R. F. Wang, M. H. Lu, and C. E. Cerniglia, "The effect of food restriction on the composition of intestinal microflora in rats," Experimental Gerontology, vol. 33, no. 3, pp. 239-247, 1998.

[190] A. Cresci, C. Orpianesi, S. Silvi, V. Mastrandrea, and P. Dolara, "The effect of sucrose or starch-based diet on shortchain fatty acids and faecal microflora in rats," Journal of Applied Microbiology, vol. 86, no. 2, pp. 245-250, 1999.

[191] S. Silvi, C. J. Rumney, A. Cresci, and I. R. Rowland, "Resistant starch modifies gut microflora and microbial metabolism in human flora-associated rats inoculated with faeces from Italian and UK donors," Journal of Applied Microbiology, vol. 86, no. 3, pp. 521-530, 1999.

[192] R. Sharma and U. Schumacher, "The diet and gut microflora influence the distribution of enteroendocrine cells in the rat intestine," Experientia, vol. 52, no. 7, pp. 664-670, 1996.

[193] A. Gostner, M. Blaut, V. Schäffer et al., "Effect of isomalt consumption on faecal microflora and colonic metabolism in healthy volunteers," British Journal of Nutrition, vol. 95, no. 1, pp. 40-50, 2006.

[194] A. Högberg, J. E. Lindberg, T. Leser, and P. Wallgren, "Influence of cereal non-starch polysaccharides on ileocaecal and rectal microbial populations in growing pigs," Acta Veterinaria Scandinavica, vol. 45, no. 1-2, pp. 87-98, 2004.

[195] G. R. Gibson, H. M. Probert, J. Van Loo, R. A. Rastall, and M. B. Roberfroid, "Dietary modulation of the human colonic microbiota: updating the concept of prebiotics," Nutrition Research Reviews, vol. 17, no. 2, pp. 259-275, 2004.

[196] B. Kleessen, L. Hartmann, and M. Blaut, "Oligofructose and long-chain inulin: influence on the gut microbial ecology of rats associated with a human faecal flora," British Journal of Nutrition, vol. 86, no. 2, pp. 291-300, 2001.
[197] Y. Bouhnik, A. Attar, F. A. Joly, M. Riottot, F. Dyard, and B. Flourié, "Lactulose ingestion increases faecal bifidobacterial counts: a randomised double-blind study in healthy humans," European Journal of Clinical Nutrition, vol. 58, no. 3, pp. 462-466, 2004.

[198] Y. Bouhnik, L. Raskine, G. Simoneau, D. Paineau, and F. Bornet, "The capacity of short-chain fructo-oligosaccharides to stimulate faecal bifidobacteria: a dose-response relationship study in healthy humans," Nutrition Journal, vol. 5, article 8, 2006.

[199] S. J. Langlands, M. J. Hopkins, N. Coleman, and J. H. Cummings, "Prebiotic carbohydrates modify the mucosa associated microflora of the human large bowel," Gut, vol. 53, no. 11, pp. 1610-1616, 2004.

[200] I. M. J. Bovee-Oudenhoven, S. J. M. Ten Bruggencate, M. L. G. Lettink-Wissink, and R. Van Der Meer, "Dietary fructooligosaccharides and lactulose inhibit intestinal colonisation but stimulate translocation of salmonella in rats," Gut, vol. 52, no. 11, pp. 1572-1578, 2003.

[201] S. O'Flaherty, D. M. Saulnier, B. Pot, and J. Versalovic, "How can probiotics and prebiotics impact mucosal immunity?" Gut Microbes, vol. 1, no. 5, p. 293, 2010.

[202] D. Heilpern and A. Szilagyi, "Manipulation of intestinal microbial flora for therapeutic benefit in inflammatory bowel diseases: review of clinical trials of probiotics, prebiotics and synbiotics," Reviews on Recent Clinical Trials, vol. 3, no. 3, pp. 167-184, 2008.

[203] V. E. Rolfe, P. J. Fortun, C. J. Hawkey, and F. Bath-Hextall, "Probiotics for maintenance of remission in Crohn's disease," Cochrane Database of Systematic Reviews, no. 4, p. CD004826, 2006.

[204] C. L. Kwan, N. E. Diamant, G. Pope, K. Mikula, D. J. Mikulis, and K. D. Davis, "Abnormal forebrain activity in functional bowel disorder patients with chronic pain," Neurology, vol. 65, no. 8, pp. 1268-1277, 2005.

[205] F. Azpiroz, M. Bouin, M. Camilleri et al., "Mechanisms of hypersensitivity in IBS and functional disorders," Neurogastroenterology and Motility, vol. 19, supplement 1, pp. 62-88, 2007.

[206] K. Tillisch and E. A. Mayer, "Pain perception in irritable bowel syndrome," CNS Spectrums, vol. 10, no. 11, pp. 877882, 2005.

[207] U. Blankstein, J. Chen, N. E. Diamant, and K. D. Davis, "Altered brain structure in irritable bowel syndrome: potential contributions of pre-existing and disease-driven factors," Gastroenterology, vol. 138, no. 5, pp. 1783-1789, 2010.

[208] M. P. Jones, J. B. Dilley, D. Drossman, and M. D. Crowell, "Brain-gut connections in functional GI disorders: anatomic and physiologic relationships," Neurogastroenterology and Motility, vol. 18, no. 2, pp. 91-103, 2006.

[209] H. Törnblom, G. Lindberg, B. Nyberg, and B. Veress, "Fullthickness biopsy of the jejunum reveals inflammation and enteric neuropathy in irritable bowel syndrome," Gastroenterology, vol. 123, no. 6, pp. 1972-1979, 2002.

[210] W. E. Whitehead, M. D. Crowell, J. C. Robinson, B. R. Heller, and M. M. Schuster, "Effects of stressful life events on bowel symptoms: subjects with irritable bowel syndrome compared with subjects without bowel dysfunction," Gut, vol. 33, no. 6, pp. 825-830, 1992.

[211] J. E. Kellow, G. M. Eckersley, and M. P. Jones, "Enhanced perception of physiological intestinal motility in the irritable bowel syndrome," Gastroenterology, vol. 101, no. 6, pp. 16211627, 1991. 
[212] J. Serra, F. Azpiroz, and J. R. Malagelada, "Impaired transit and tolerance of intestinal gas in the irritable bowel syndrome," Gut, vol. 48, no. 1, pp. 14-19, 2001.

[213] M. Ortiz Lucas, P. Saz Peiró, and J. J. Sebastián Domingo, "Irritable bowel syndrome immune hypothesis. Part two: the role of cytokines," Revista Espanola de Enfermedades Digestivas, vol. 102, no. 12, pp. 711-717, 2010.

[214] C. Tana, Y. Umesaki, A. Imaoka, T. Handa, M. Kanazawa, and S. Fukudo, "Altered profiles of intestinal microbiota and organic acids may be the origin of symptoms in irritable bowel syndrome," Neurogastroenterology and Motility, vol. 22, no. 5, pp. 512-519, 2010.

[215] V. S. Chadwick, W. Chen, D. Shu et al., "Activation of the mucosal immune system in irritable bowel syndrome," Gastroenterology, vol. 122, no. 7, pp. 1778-1783, 2002.

[216] J. Keohane, C. O’Mahony, L. O’Mahony, S. O’Mahony, E. M. Quigley, and F. Shanahan, "Irritable bowel syndrome-type symptoms in patients with inflammatory bowel disease: a real association or reflection of occult inflammation?" The American Journal of Gastroenterology, vol. 105, no. 8, pp. 1788-1795, 2010.

[217] F. Costa, M. G. Mumolo, M. Bellini et al., "Role of faecal calprotectin as non-invasive marker of intestinal inflammation," Digestive and Liver Disease, vol. 35, no. 9, pp. 642-647, 2003.

[218] S. J. Shepherd and P. R. Gibson, "Fructose malabsorption and symptoms of irritable bowel syndrome: guidelines for effective dietary management," Journal of the American Dietetic Association, vol. 106, no. 10, pp. 1631-1639, 2006.

[219] K. L. E. Dear, M. Elia, and J. O. Hunter, "Do interventions which reduce colonic bacterial fermentation improve symptoms of irritable bowel syndrome?" Digestive Diseases and Sciences, vol. 50, no. 4, pp. 758-766, 2005.

[220] D. K. Ong, S. B. Mitchell, J. S. Barrett et al., "Manipulation of dietary short chain carbohydrates alters the pattern of gas production and genesis of symptoms in irritable bowel syndrome," Journal of Gastroenterology and Hepatology, vol. 25, no. 8, pp. 1366-1373, 2010.

[221] H. M. Staudacher, K. Whelan, P. M. Irving, and M. C. E. Lomer, "Comparison of symptom response following advice for a diet low in fermentable carbohydrates (FODMAPs) versus standard dietary advice in patients with irritable bowel syndrome," Journal of Human Nutrition and Dietetics, vol. 24, no. 5, pp. 487-495, 2011.

[222] F.M. Ruemmele, "Early programming effects of nutritionlife-long consequences?" Annals of Nutrition and Metabolism, vol. 58, supplement 2, pp. 5-6, 2011.

[223] F. M. Ruemmele, C. C. Roy, E. Levy, and E. G. Seidman, "Nutrition as primary therapy in pediatric Crohn's disease: fact or fantasy?" Journal of Pediatrics, vol. 136, no. 3, pp. 285291, 2000.

[224] H. Lorenz-Meyer, P. Bauer, C. Nicolay et al., "Omega3 fatty acids and low carbohydrate diet for maintenance of remission in Crohn's disease. A randomized controlled multicenter trial," Scandinavian Journal of Gastroenterology, vol. 31, no. 8, pp. 778-785, 1996.

[225] R. B. Gearry, P. M. Irving, J. S. Barrett, D. M. Nathan, S. J. Shepherd, and P. R. Gibson, "Reduction of dietary poorly absorbed short-chain carbohydrates (FODMAPs) improves abdominal symptoms in patients with inflammatory bowel disease-a pilot study," Journal of Crohn's and Colitis, vol. 3, no. 1, pp. 8-14, 2009.

[226] C. Hallert, M. Kaldma, and B. G. Petersson, "Ispaghula husk may relieve gastrointestinal symptoms in ulcerative colitis in remission," Scandinavian Journal of Gastroenterology, vol. 26, no. 7, pp. 747-750, 1991.

[227] F. Fernández-Bañares, J. Hinojosa, J. L. Sânchcz-Lombraña et al., "Randomized clinical trial of Plantago ovata seeds (Dietary fiber) as compared with mesalamine in maintaining remission in ulcerative colitis," American Journal of Gastroenterology, vol. 94, no. 2, pp. 427-433, 1999.

[228] K. Mitsuyama, T. Saiki, O. Kanauchi et al., "Treatment of ulcerative colitis with germinated barley foodstuff feeding: a pilot study," Alimentary Pharmacology and Therapeutics, vol. 12, no. 12, pp. 1225-1230, 1998.

[229] O. Kanauchi, K. Mitsuyama, T. Homma et al., "Treatment of ulcerative colitis patients by long-term administration of germinated barley foodstuff: multi-center open trial," International Journal of Molecular Medicine, vol. 12, no. 5, pp. 701-704, 2003.

[230] Z. Faghfoori, L. Navai, R. Shakerhosseini, M. H. Somi, Z. Nikniaz, and M. F. Norouzi, "Effects of an oral supplementation of germinated barley foodstuff on serum tumour necrosis factor- $\alpha$, interleukin- 6 and -8 in patients with ulcerative colitis," Annals of Clinical Biochemistry, vol. 48, no. 3, pp. 233-237, 2011.

[231] H. Hanai, O. Kanauchi, K. Mitsuyama et al., "Germinated barley foodstuff prolongs remission in patients with ulcerative colitis," International Journal of Molecular Medicine, vol. 13, no. 5, pp. 643-647, 2004.

[232] F. Casellas, N. Borruel, A. Torrejón et al., "Oral oligofructoseenriched inulin supplementation in acute ulcerative colitis is well tolerated and associated with lowered faecal calprotectin," Alimentary Pharmacology and Therapeutics, vol. 25, no. 9, pp. 1061-1067, 2007.

[233] A. Szilagyi, J. Rivard, and I. Shrier, "Diminished efficacy of colonic adaptation to lactulose occurs in patients with inflammatory bowel disease in remission," Digestive Diseases and Sciences, vol. 47, no. 12, pp. 2811-2822, 2002.

[234] A. Hafer, S. Krämer, S. Duncker, M. Krüger, M. P. Manns, and S. C. Bischoff, "Effect of oral lactulose on clinical and immunohistochemical parameters in patients with inflammatory bowel disease: a pilot study," BMC Gastroenterology, vol. 7, article 36, 2007.

[235] T. A. Hussey, R. M. Issenman, and S. Persad, "Nutrition therapy in pediatric therapy improves nutrition status and decreases inflammation," Journal of Pediatric Gastroenterology, vol. 37, p. 34, 2003.

[236] J. O. Lindsay, K. Whelan, A. J. Stagg et al., "Clinical, microbiological, and immunological effects of fructo-oligosaccharide in patients with Crohn's disease," Gut, vol. 55, no. 3, pp. 348355, 2006.

[237] J. L. Benjamin, C. R.H. Hedin, A. Koutsoumpas et al., "Randomised, double-blind, placebo-controlled trial of fructooligosaccharides in active Crohn's disease," Gut, vol. 60, no. 7, pp. 923-929, 2011.

[238] C. F. M. Welters, E. Heineman, F. B. J. M. Thunnissen, A. E. J. M. Van den Bogaard, P. B. Soeters, and C. G. M. I. Baeten, "Effect of dietary inulin supplementation on inflammation of pouch mucosa in patients with an ileal pouch-anal anastomosis," Diseases of the Colon and Rectum, vol. 45, no. 5, pp. 621-627, 2002.

[239] J. Kuisma, S. Mentula, H. Jarvinen, A. Kahri, M. Saxelin, and M. Farkkila, "Effect of Lactobacillus rhamnosus GG on ileal pouch inflammation and microbial flora," Alimentary Pharmacology and Therapeutics, vol. 17, no. 4, pp. 509-515, 2003. 
[240] E. Furrie, S. Macfarlane, A. Kennedy et al., "Synbiotic therapy (Bifidobacterium longum/Synergy 1) initiates resolution of inflammation in patients with active ulcerative colitis: a randomised controlled pilot trial," Gut, vol. 54, no. 2, pp. 242-249, 2005.

[241] S. Fujimori, K. Gudis, K. Mitsui et al., "A randomized controlled trial on the efficacy of synbiotic versus probiotic or prebiotic treatment to improve the quality of life in patients with ulcerative colitis," Nutrition, vol. 25, no. 5, pp. 520-525, 2009.

[242] I. Chermesh, A. Tamir, R. Reshef et al., "Failure of synbiotic 2000 to prevent postoperative recurrence of Crohn's disease," Digestive Diseases and Sciences, vol. 52, no. 2, pp. 385-389, 2007.

[243] S. Fujimori, A. Tatsuguchi, K. Gudis et al., "High dose probiotic and prebiotic cotherapy for remission induction of active Crohn's disease," Journal of Gastroenterology and Hepatology, vol. 22, no. 8, pp. 1199-1204, 2007.

[244] H. Steed, G. T. MacFarlane, K. L. Blackett et al., "Clinical trial: the microbiological and immunological effects of synbiotic consumption - a randomized double-blind placebocontrolled study in active Crohn's disease," Alimentary Pharmacology and Therapeutics, vol. 32, no. 7, pp. 872-883, 2010.

[245] G. Friedman and J. George, "Treatment of refractory pouchitis with prebiotic and probiotic therapy," Gastroenterology, vol. 118, p. G4167, 2000.

[246] A. Szilagyi, "Review article: lactose-a potential prebiotic," Alimentary Pharmacology and Therapeutics, vol. 16, no. 9, pp. 1591-1602, 2002.

[247] S. R. Hertzler and D. A. Savaiano, "Colonic adaptation to daily lactose feeding in lactose maldigesters reduces lactose intolerance," American Journal of Clinical Nutrition, vol. 64, no. 2, pp. 232-236, 1996.

[248] F. Briet, P. Pochart, P. Marteau, B. Flourie, E. Arrigoni, and J. C. Rambaud, "Improved clinical tolerance to chronic lactose ingestion in subjects with lactose intolerance: a placebo effect?" Gut, vol. 41, no. 5, pp. 632-715, 1997.

[249] T. Jiang and D. A. Savaiano, "In vitro lactose fermentation by human colonic bacteria is modified by Lactobacillus acidophilus supplementation," Journal of Nutrition, vol. 127, no. 8, pp. 1489-1495, 1997.

[250] T. Jiang and D. A. Savaiano, "Modification of colonic fermentation by bifidobacteria and $\mathrm{pH}$ In Vitro: impact on lactose metabolism, short-chain fatty acid, and lactate production," Digestive Diseases and Sciences, vol. 42, no. 11, pp. 2370-2377, 1997.

[251] H. A. Mäkivuokko, M. T. Saarinen, A. C. Ouwehand, and N. E. Rautonen, "Effects of lactose on colon microbial community structure and function in a four-stage semicontinuous culture system," Bioscience, Biotechnology and Biochemistry, vol. 70, no. 9, pp. 2056-2063, 2006.

[252] D. Paineau, F. Payen, S. Panserieu et al., "The effects of regular consumption of short-chain fructo-oligosaccharides on digestive comfort of subjects with minor functional bowel disorders," British Journal of Nutrition, vol. 99, no. 2, pp. 311$318,2008$.

[253] D. B. A. Silk, A. Davis, J. Vulevic, G. Tzortzis, and G. R. Gibson, "Clinical trial: the effects of a trans-galactooligosaccharide prebiotic on faecal microbiota and symptoms in irritable bowel syndrome," Alimentary Pharmacology and Therapeutics, vol. 29, no. 5, pp. 508-518, 2009. 


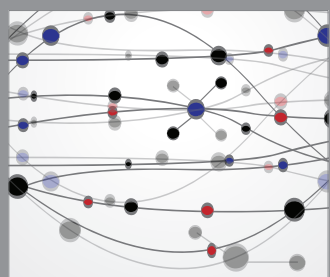

The Scientific World Journal
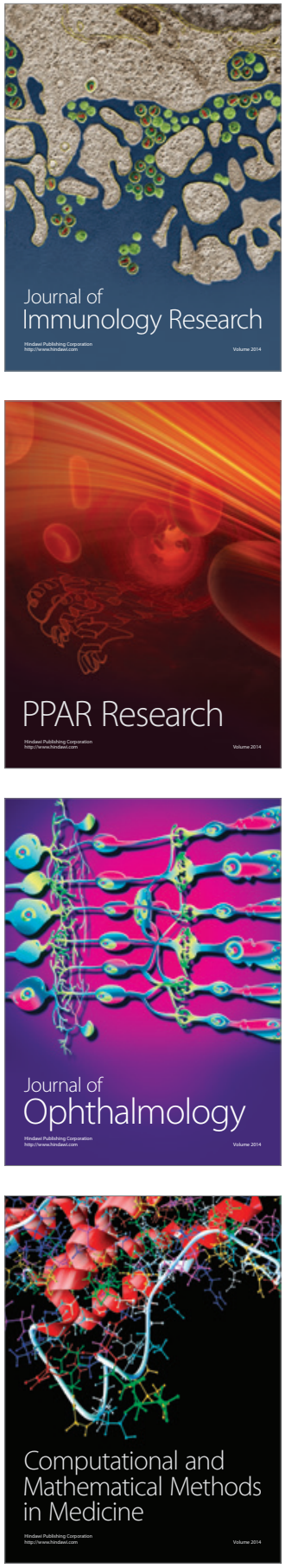

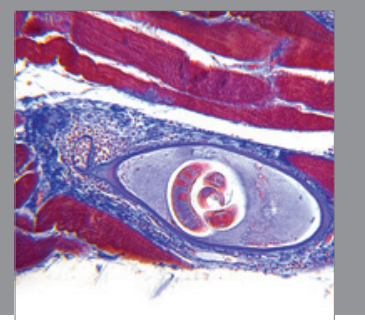

Gastroenterology

Research and Practice
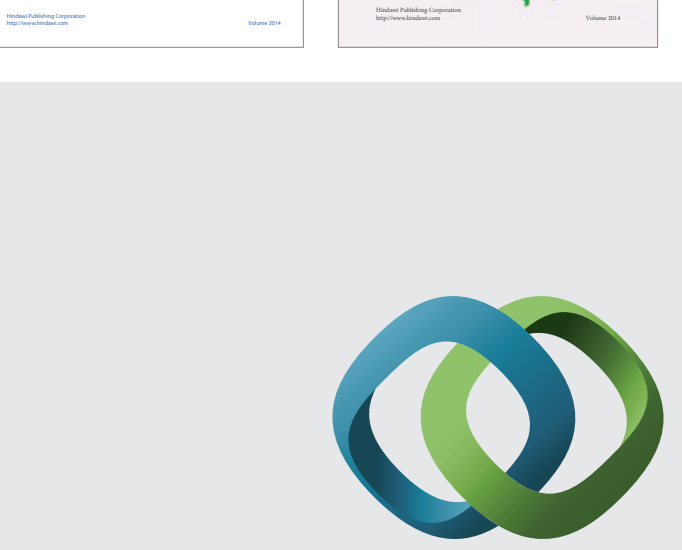

\section{Hindawi}

Submit your manuscripts at

http://www.hindawi.com
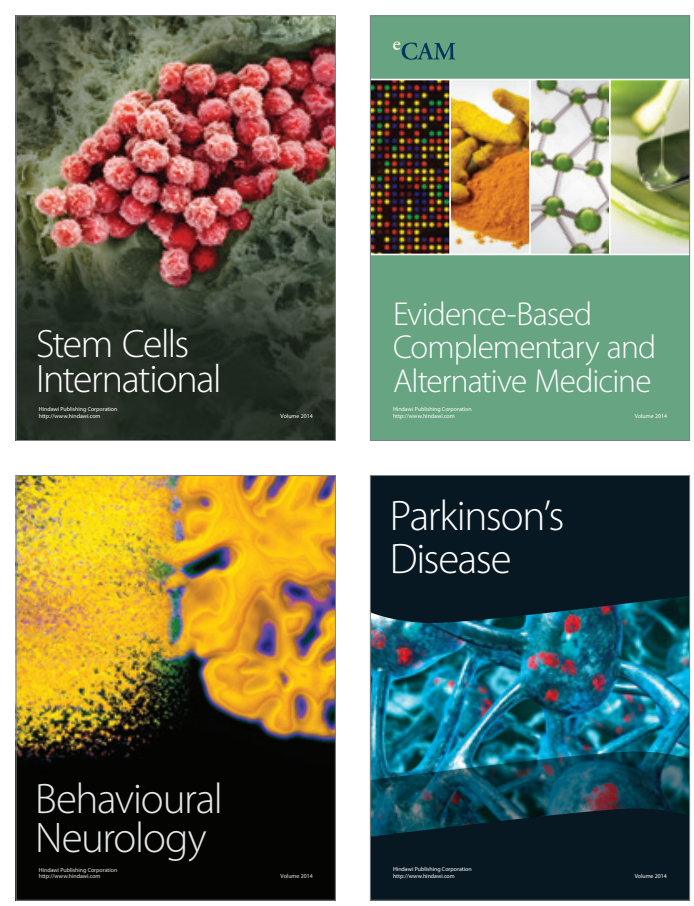

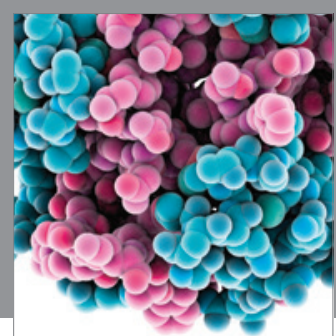

Journal of
Diabetes Research

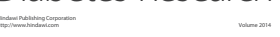

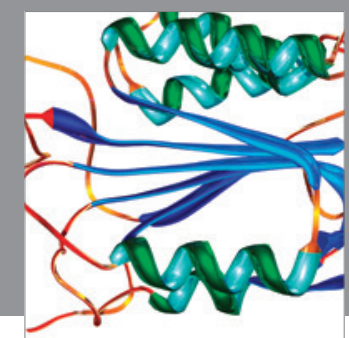

Disease Markers
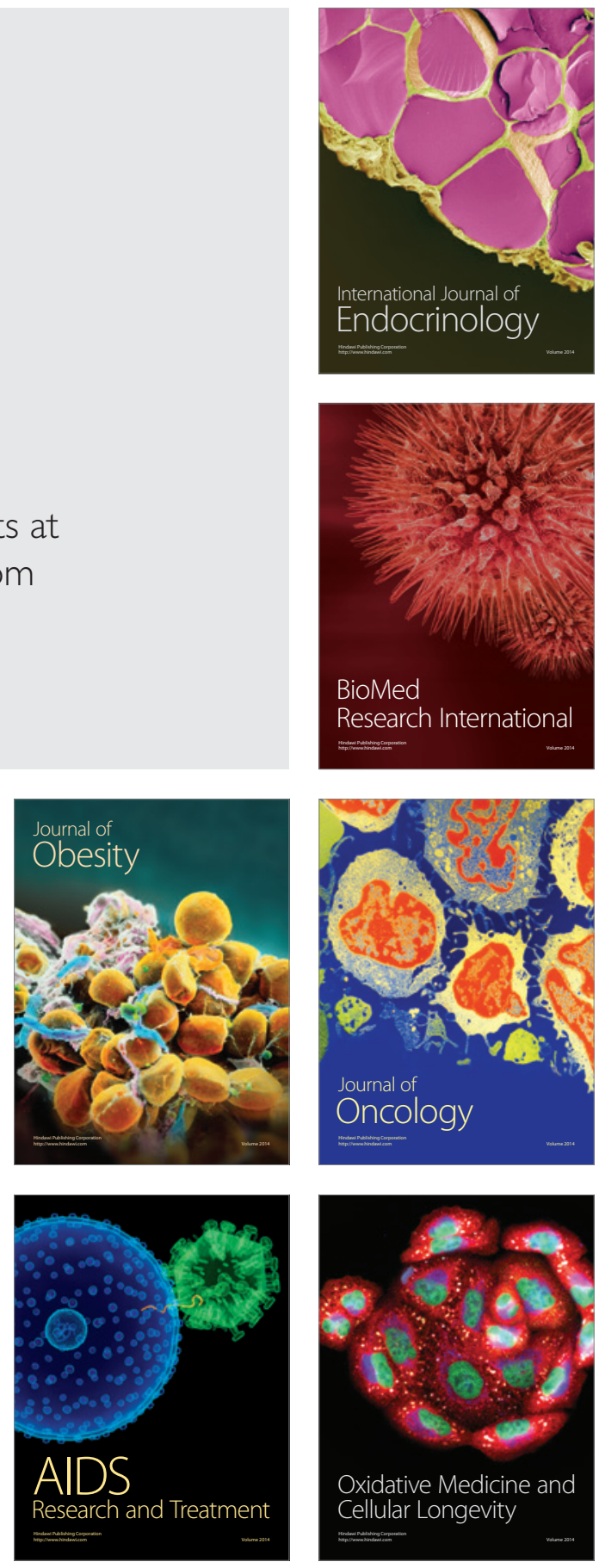